\title{
Loss of Semaphorin-Neuropilin-1 Signaling Causes Dysmorphic Vascularization Reminiscent of Alveolar Capillary Dysplasia
}

\author{
Stephen Joza, ${ }^{* \dagger}$ Jinxia Wang, ${ }^{*}$ Emily Fox, ${ }^{* \neq}$ \\ Valerie Hillman, ${ }^{\S}$ Cameron Ackerley, ${ }^{*}$ and \\ Martin Post ${ }^{\star \dagger \ddagger}$ \\ From the Physiology and Experimental Medicine Program,* \\ Hospital for Sick Children, Toronto, Ontario; the Departments of \\ Laboratory Medicine and Pathobiology ${ }^{\dagger}$ and Physiology, \\ University of Toronto, Toronto, Ontario; and the Department of \\ Animal and Poultry Sciences, ${ }^{\S}$ University of Guelph, Guelph, \\ Ontario, Canada
}

Respiratory diseases of the newborn can arise from the disruption of essential angiogenic pathways. Neuropilin-1 (NRP1), which is a critical receptor implicated in systemic vascular growth and remodeling, binds two distinct ligand families: vascular endothelial growth factor (VEGF) and class 3 semaphorins (SEMA3). Although the function of VEGF-NRP1 interactions in vascular development is well described, the importance of SEMA3-NRP1 signaling in systemic or pulmonary vascular morphogenesis is debated. We sought to characterize the effect of deficient SEMA3NRP1 signaling on fetal pulmonary vascular development in a mouse model. Temporospatial expression of $N r p 1$ and Sema 3 mRNA and protein during murine fetal lung development was investigated, and the development of the pulmonary vasculature in transgenic mice deficient in Sema3-Nrp1 signaling was examined by histology, immunostaining, and electron microscopy. Loss of Sema3-Nrp1 signaling resulted in acute respiratory distress and high neonatal mortality. Pathohistological examination of mutants revealed immature and atelectatic regions in the lung, severely reduced capillary density, thickened alveolar septa containing centrally located dilated capillaries, hypertensive changes in arteriolar walls, anomalous and misaligned pulmonary veins, and reduced pulmonary surfactant secretion. Notably, many features are reminiscent of the fatal pulmonary disorder alveolar capillary dysplasia. These findings indicate a critical role for Sema3-Nrp1 signaling in fetal pulmonary development, which may have clinical relevance for treat- ment of various neonatal respiratory disorders, including alveolar capillary dysplasia. (Am J Pathol 2012, 181: 2003-201 7; http://dx.doi.org/10.1016/j.ajpath.2012.08.037)

The lung parenchyma is formed through extensive branching, subdivision, and maturation of the terminal airways and microvasculature. Essential to this process is an intimate signaling relationship between epithelial and vascular endothelial cells, which culminates in the formation of the alveolar-capillary interface by the fusion of their basal laminae. ${ }^{1}$

Renewed interest in epithelial-endothelial interplay has arisen from evidence that disruption of angiogenic pathways or endothelial cell function results in dysplastic pulmonary development, ${ }^{2,3}$ which can be partially restored by angiogenic treatment. ${ }^{4-6}$ Clinically, the consequences of disrupted epithelial-endothelial crosstalk is dramatically exemplified by the rare disorder alveolar capillary dysplasia (ACD), which exhibits extreme microvascular paucity, impaired formation of the alveolar-capillary interface, and resultant fatal hypoxemia. ${ }^{7}$ ACD-like phenotypes have been observed in mice deficient for the essential angiogenic factors endothelial nitric oxide synthase (eNOS) and vascular endothelial growth factor (VEGF), ${ }^{1,8}$ a finding that highlights the importance of vascular signaling in establishing the alveolar-capillary interface.

Class 3 semaphorins (SEMA3) are a family of secreted glycoproteins implicated in various aspects of morpho-

Supported by an operating grant (MOP-77751) from the Canadian Institutes for Health Research, an infrastructure grant (CSCCD) from the Canadian Foundation of Innovation, an Ontario Graduate Scholarship and additional support from Restracomp, Hospital for Sick Children (S.J.), and M.P. holds a Canadian Research Chair in Fetal, Neonatal and Maternal Health

Accepted for publication August 15, 2012.

Supplemental material for this article can be found at http://ajp. amjpathol.org or at http://dx.doi.org/10.1016/j.ajpath.2012.08.037.

Address reprint requests to Martin Post, Ph.D., Physiology and Experimental Medicine, Hospital for Sick Children, 555 University Ave., Toronto, ON, M5G 1X8, Canada. E-mail: martin.post@sickkids.ca. 
genesis, including axon guidance, epithelial branching, and vascular patterning ${ }^{9-12}$ Combinations of the transmembrane receptors NRP1 and NRP2, together with type $A$ and $D$ plexins, form ligand binding and signal transduction complexes with differing SEMA3 affinity and downstream effects. ${ }^{13}$ In addition, NRP1 and NRP2 bind members of the VEGF family, which mediate proangiogenic events through enhanced VEGF interactions with its canonical receptor, VEGFR-2, as well via VEGFR-2independent signaling. ${ }^{14-16}$ Given the ability of NRP1 to bind two distinct ligand families, its expression in the vascular endothelium during development, and the severe cardiac and peripheral vascular defects observed in certain Nrp1 and Sema3 transgenics, ${ }^{17-19}$ the idea that SEMA3-NRP1 signaling could mediate opposing or additive functions to VEGF-mediated angiogenesis and vascular homeostasis is attractive. Indeed, recent studies have indicated essential roles for SEMA3 in both normal and pathological vascular development, many of which mirror or directly oppose the known functions of VEGF. 12,20,21 In contrast, other researchers have maintained that SEMA3-NRP1 interactions are uninvolved in vascular development. ${ }^{19,22}$

In the present study, we determined the role of Sema3Nrp1 signaling during fetal pulmonary development in a mouse model. Selective loss of Sema3-Nrp1 signaling while maintaining Vegf-Nrp1 interactions in transgenic $\mathrm{Nrp}{ }^{\mathrm{Sema}}$ - mice resulted in respiratory distress and high neonatal mortality. Histological examination revealed vascular anomalies reminiscent of ACD, including severely reduced capillary density, thickened alveolar septa containing centrally located capillaries, and hypertensive changes in arteriolar walls. We concluded, therefore, that the early postnatal respiratory distress and mortality observed in the majority of $\mathrm{Nrp}{ }^{\mathrm{Sema}-}$ mice arises from aberrant pulmonary microvascular development and disruption of parenchymal morphogenesis.

\section{Materials and Methods}

\section{Animals}

All protocols were in accordance with Canadian Council of Animal Care guidelines and were approved by the Animal Care and Use Committee of the Hospital for Sick Children, Toronto, ON, Canada. Heterozygous Nrp ${ }^{\text {Sema- }}$ mice $^{19}$ were obtained from the Jackson Laboratory (005245; Bar Harbor, ME) and interbred. Wildtype littermates were used as controls.

Primary culture of embryonic day 19.5 (E19.5) fetal rat lung cells was performed as described previously. ${ }^{23} \mathrm{Pu}$ rity was confirmed by cytokeratin-18 and vimentin RTPCR (see Supplemental Figure S1 at $h$ ttp://ajp.amjpathol. org). For the isolation of conditioned medium, epithelial and mesenchymal cells were grown to confluence, rinsed, and then starved in Dulbecco's modified Eagle's medium (DMEM) for 16 hours. After another rinse, $5 \mathrm{~mL}$ of fresh DMEM was added for each T-75 flask, and the cells were incubated for 24 hours. Conditioned medium was then pooled from approximately three flasks and was isolated from floating cells via centrifugation. For immunoblotting, conditioned medium was concentrated approximately 100-fold using Amicon Ultra-15 centrifugal filters with a 10-kDa minimum cutoff (Millipore, Billerica, MA).

\section{qPCR Gene Expression}

Tissues were homogenized in TRlzol reagent (Invitrogen; Life Technologies, Burlington, ON, Canada). RNA was reverse transcribed using SuperScript III (Invitrogen; Life Technologies) and quantitative real-time PCR (qPCR) was performed using a StepOne real-time PCR system (Applied Biosystems; Life Technologies, Foster City, CA). Fold change was calculated with normalization to $18 S^{24}$ Primer sequences are given in Table 1.

\section{Immunohistochemistry}

Details of antibodies are given in Table 2. Immunohistochemistry was performed as described previously. ${ }^{27}$ Heat-induced antigen retrieval was performed by incubation in $10 \mathrm{mmol} / \mathrm{L}$ sodium citrate, $\mathrm{pH} 6.0$, in a microwave pressure cooker; enzymatic antigen retrieval was performed by incubating in $20 \mu \mathrm{g} / \mathrm{mL}$ proteinase $\mathrm{K}$ solution.

\section{Electron Microscopy}

After exsanguination, anesthetized mice were tracheally intubated and lungs filled with $2.5 \%$ glutaraldehyde under constant pressure $\left(10 \mathrm{~cm} \mathrm{H}_{2} \mathrm{O}\right)$ for 5 minutes. Tissues were then processed as described previously. ${ }^{28}$ Ultrathin sections were stained in uranyl acetate and lead citrate and examined under a transmission electron microscope (TEM) (JEM1011; JEOL USA, Peabody, MA).

\section{Morphometry of Resin-Embedded Lung}

All slides and images were analyzed in a masked manner. Images of toluidine blue-stained $1-\mu \mathrm{m}$ sections were captured using a Nikon digital camera and a 100x oil immersion lens. Images were analyzed using ImageJ software $\left(\mathrm{NIH}\right.$, Bethesda, MD) and the total area $\left(\mathrm{mm}^{2}\right)$ of alveolar space was calculated. Both lamellar body-containing type II cell and vessel profiles were counted within these areas and the density of either profile expressed as type II cells or alveolar vessels per area $\left(\mathrm{mm}^{2}\right)$. A minimum of 50 fields from each animal and two animals from each group were analyzed. VSMC-vessel association was determined from analyzing $>10 \mathrm{~mm}$ of pulmonary artery and $>5 \mathrm{~mm}$ of pulmonary vein. Length of arterioles and venules were measured, and the number of VSMCs per millimeter were counted. Capillary-pneumocyte adhesion was determined from TEM images. Endothelial and type I cells were measured along the length of the basal lamina. Any portion with breaks in association of the basal lamina between any of the components was excluded. The percentage of cell adhesion to the basal lamina was calculated by dividing the length of cell ad- 
Table 1. Primer Sequences Synthesized for qPCR and RT-PCR

\begin{tabular}{|c|c|c|}
\hline Target & Primer or Probe & Sequence or catalog number \\
\hline \multirow[t]{2}{*}{$18 S$} & Forward & 5'-GTAACCCGTTGAACCCCATT-3' \\
\hline & Reverse & $5^{\prime}$-CCATCCAATCGGTAGTAGCG-5' \\
\hline \multirow[t]{2}{*}{ Aqp5 } & Forward & 5'-TATCCATTGGCTTGTCGGTCAC-3' \\
\hline & Reverse & $5^{\prime}$-TCAGCGAGGAGGGGAAAAGCAAGTA-3' \\
\hline \multirow{2}{*}{ Cytokeratin-18 } & Forward & $5^{\prime}$-CATCCACACGAAGACCACCAGTG-3' \\
\hline & Reverse & 5'-GCTGGTACTCTGGCTGGTCCCTA-3' \\
\hline \multirow[t]{2}{*}{ eNOS } & Forward & $5^{\prime}-$ TCCGGAAGGCGTTTGATC-3' \\
\hline & Reverse & $5^{\prime}-$ GCCAAATGTGCTGGTCACC-3' \\
\hline \multirow[t]{2}{*}{ Foxf1 } & Forward & $5^{\prime}$-AGCAGCCATACCTTCACCAA-3' \\
\hline & Reverse & $5^{\prime}$-TAAGATCCTCCGCCTGTTGT-3' \\
\hline \multirow[t]{2}{*}{ Nrp1 } & Forward & 5'-CACCAAAGATGTCTGAGATAATCCT-3' \\
\hline & Reverse & $5^{\prime}$-GCTGTAGTTGGCTGAGAAACCTTCC-3' \\
\hline \multirow{2}{*}{ Sema3c } & Forward & $5^{\prime}$-ATCTGGCAAAGGACGATGCTCTTTC-3' \\
\hline & Reverse & $5^{\prime}$-GTGCGTCCACAAACATGGGTTCACT-3' \\
\hline \multirow[t]{2}{*}{ Sema3f } & Forward & $5^{\prime}$-GCTTCCAGCCACACCTAGAGTC-3' \\
\hline & Reverse & $5^{\prime}$-TAGTCCTTGCTGCCCACATACA-3' \\
\hline \multirow[t]{2}{*}{ Sp-C } & Forward & $5^{\prime}-$ TGGAGAGTCCACCGGATTAC-3' \\
\hline & Reverse & $5^{\prime}$-GAGCAGAGCCCCTACAATCA-3' \\
\hline \multirow[t]{2}{*}{$\mathrm{T} 1 \alpha$} & Forward & $5^{\prime}$ - CAAGAAAACAAGTCACCCCAATAGAGATA-3' \\
\hline & Reverse & $5^{\prime}$-GAAGATCCCTCCGACGAAGCCAATG-3' \\
\hline \multirow[t]{2}{*}{ Total Vegf } & Forward & $5^{\prime}-$ TGTACCTCCACCATGCCAAGT-3' \\
\hline & Reverse & 5'-CACAGGACGGCTTGAAGATG-3' \\
\hline \multirow[t]{2}{*}{ Vegfr1 } & Forward & $5^{\prime}$ - GAAGCAAGGAGGGCCTCTGATGGTG-3' \\
\hline & Reverse & 5'-GCCAGGTCCCGATGAATGCACTTC-3' \\
\hline \multirow[t]{2}{*}{ Vegfr2 } & Forward & $5^{\prime}$-CATCGAGCCCTCATGTCTGAA-3' \\
\hline & Reverse & 5'-GCGTGCCCCTTTGCTCTTATA-3' \\
\hline \multirow[t]{2}{*}{ Vimentin } & Forward & $5^{\prime}$-CTCCTACGGTTCACAGCCACTG-3' \\
\hline & Reverse & 5'-GTGTTCTTGAACTCGGTGTTGAT-3' \\
\hline Abca3 & Qiagen Primer Assay & QT00143822 \\
\hline Sema3a & Qiagen Primer Assay & QT00192941 \\
\hline \multirow{4}{*}{$\begin{array}{l}\text { Sp-B } \\
\text { Ang1 }\end{array}$} & Qiagen Primer Assay & QT01537529 \\
\hline & Forward & 5'-GCAAATGCGCTCCTCATGCTA-3' \\
\hline & Reverse & 5'-GGAGTAACTGGGCCCTTTGAA-3' \\
\hline & Probe & FAM-AGGTTGGTGGTTCCATCCCTGTGG-TAMRA \\
\hline \multirow[t]{3}{*}{ Ang2 } & Forward & $5^{\prime}-$ TGACAGCCACGGTCAACAAC- $3^{\prime}$ \\
\hline & Reverse & $5^{\prime}$-ACGGATAGCAACCGAGCTCTT-3' \\
\hline & Probe & FAM-CAGCAGCATGACCTAATGGAGACCGTC-TAMRA \\
\hline \multirow[t]{2}{*}{ Tie2 } & Forward & $5^{\prime}$-AACATCCCTCACCTGCATTGC-3' \\
\hline & Reverse & $5^{\prime}-$ TTTCGGCCATTCTCTGGTCAC-3' \\
\hline \multirow[t]{3}{*}{$\operatorname{Vegf}_{120}$} & Forward & $5^{\prime}$-AGCAGATGTGAATGCAGACCAA- $3^{\prime}$ \\
\hline & Reverse & $5^{\prime}$-СTCСTTCCTGCCAGCCTG-3' \\
\hline & Probe & FAM-ACAAAGCCAGAAAAATGTGACAAGCCAA-BHQ \\
\hline \multirow{3}{*}{ Vegf $_{164}$} & Forward & $5^{\prime}$-CATAGAGAGAATGAGCTTCCTACAGC-3' \\
\hline & Reverse & 5'-TGCTTTCTCCGCTCTGAACA-3' \\
\hline & Probe & FAM-AGAACAAAGCCAGAAAATCACTGTGAGCCTT-BHQ \\
\hline \multirow{3}{*}{ Vegf $_{188}$} & Forward & $5^{\prime}-$ CGAAAGCGCAAGAAATCCC-3' \\
\hline & Reverse & 5'-TGCTTTCTCCGCTCTGAACA-3' \\
\hline & Probe & FAM-TAAATCCTGGAGCGTTCACTGTGAGCC-BHQ \\
\hline
\end{tabular}

hesion by the total length of basal lamina associated with the endothelial cell/type I pneumocyte.

\section{Morphometry of Paraffin-Embedded Lung}

For tissue-to-air ratio, 40 nonoverlapping and nonatelectatic images were captured at $\times 400$ magnification from three sections per animal; sections were $>200 \mu \mathrm{m}$ apart, and the operator was masked to genotype. Images were batchprocessed using ImageJ software by color-thresholding to 8-bit black-and-white, eliminating background noise using fine particle analysis, and dividing thresholded tissue area by airspace area. For CD31/cytokeratin expression in lung at E16.5, five nonoverlapping images were captured at $\times 100$ magnification. Fluorescent channels were thresholded and total pixel area of expression was quantified using ImageJ software. For Ki-67 and proSPC measurements, positive chromogenic staining was quantified in a batch by color threshold analysis and was expressed relative to total tissue area using ImageJ software.

\section{Mass Spectral Analysis of Phosphatidylcholine}

Bronchoalveolar lavage fluid was obtained by intubating anesthetized mice at postnatal day 1 (P1) with a blunted 27.5-gauge needle and then instilling and withdrawing a single $100-\mu \mathrm{L}$ bolus of PBS three times before withdrawing and collecting the lavage fluid. Samples were pelleted at $300 \times g$ for 10 minutes and the supernatant was isolated. Samples were spiked with $1 \mu \mathrm{g}$ of deuterated 16:0/16:0 phosphatidylcholine (Avanti Polar Lipids, Alabaster, $\mathrm{AL}$ ) as an internal standard and then lipids were 
Table 2. Antibodies and Dilutions Used for IHC and IB

\begin{tabular}{|c|c|c|c|}
\hline Primary antibody (host) & Source (identifier) & Antigen retrieval & Method and dilution \\
\hline ABCA3 (goat) & Santa Cruz Biotechnology (sc-48444) & & IB 1:200 \\
\hline$\beta$-Actin (mouse) & Sigma-Aldrich (A2228) & & IB $1: 50,000$ \\
\hline $\mathrm{CT} \alpha$ (rabbit) & As described by Yang et $a^{25}$ & & IB 1:14,000 \\
\hline Pan-cytokeratin (rabbit) & Dako (Z0622) & Proteinase K & IHC 1:200 \\
\hline FAS (rabbit) & Cell Signaling Technology (3180) & & IB 1:1000 \\
\hline Ki67 & Dako (M724029) & Sodium citrate & IHC 1:100 \\
\hline NG2 (rabbit) & Millipore (AB5320) & Sodium citrate & IHC 1:200 \\
\hline NRP1 (rabbit) & Gift of Dr. David D. Ginty ${ }^{26}$ & Proteinase K & IHC 1:2000; IB 1:7500 \\
\hline NRP2 (rabbit) & Santa Cruz Biotechnology (sc-5542) & Sodium citrate & $\mathrm{IHC}: 100 x$ \\
\hline CD31 (rabbit) & Santa Cruz Biotechnology (sc-1506R) & Sodium citrate & IHC 1:2000; IB 1:15,000 \\
\hline CD31 (goat) & Santa Cruz Biotechnology (sc-1506) & Sodium citrate & IHC $1: 400$ \\
\hline CD31 (rat) & BD Pharmingen (MEC13.3) & Proteinase $\mathrm{K}$ & IHC 1:100 \\
\hline SEMA3C (goat) & Santa Cruz Biotechnology (sc-27796) & Proteinase $\mathrm{K}$ & IHC 1:100; IB 1:500 \\
\hline$\alpha$-SMA (mouse) & Neomarkers (MS-113-R7) & Proteinase $\mathrm{K}$ & IHC 1:400 \\
\hline SP-B (rabbit) & Chemicon (AB3426) & & IB 1:4000 \\
\hline ProSPC (rabbit) & Abcam (ab40879) & Sodium citrate & IHC 1:2000 \\
\hline T1 $\alpha$ (Syrian hamster) & DSHB (8.1.1) & Sodium citrate & IHC 1:200 \\
\hline VEGFR2 (rabbit) & Santa Cruz Biotechnology (sc-315) & & IB 1:2500 \\
\hline Vimentin (mouse) & Dako (M7020) & None & IHC 1:200 \\
\hline
\end{tabular}

For $\mathrm{HC}$, antigen retrieval was performed with either $10 \mathrm{mmol} / \mathrm{L}$ sodium citrate or $20 \mu \mathrm{g} / \mathrm{mL}$ proteinase $\mathrm{K}$, as described in Materials and Methods. DSHB, Developmental Studies Hybridoma Bank (University of lowa, lowa City, IA); IB, immunoblotting.

extracted. Lipids were analyzed using an API4000 mass spectrometer (MDS Sciex, Concord, ON, Canada). ${ }^{28}$

\section{Immunoblotting}

Immunoblotting was performed as described previously. ${ }^{28}$ All samples were reduced, except those for antiSP-B. Antibodies used are listed in Table 2.

\section{Fluorescent Microangiography}

Fluorescent microangiography was performed essentially as described previously. ${ }^{29}$ After the left atrium was transected, warm PBS was infused into the pulmonary circulation via the right ventricle, followed by a $250-\mu \mathrm{L}$ infusion of AlexaFluor 488-labeled fluorescent microspheres (Invitrogen; Life Technologies) diluted in lowmelt agarose. After being held on ice for 10 minutes, lungs were inflated with $4 \%$ paraformaldehyde under 10 $\mathrm{cm} \mathrm{H}_{2} \mathrm{O}$ pressure for 5 minutes. After overnight incubation in paraformaldehyde at $4^{\circ} \mathrm{C}$, lungs were washed and then stored in $70 \%$ ethanol. Left lung lobes were sectioned at $100 \mu \mathrm{m}$ using a vibrating microtome and then were mounted onto slides. Confocal $z$-stacks were imaged at $\times 100$ magnification using $5-\mu \mathrm{m}$ steps and processed using Improvision Volocity version 4.3.2 software (PerkinElmer, Waltham, MA).

\section{Lung Explant Culture}

Lung buds were isolated from E11.5 embryos as described previously. ${ }^{27}$ Branching was assessed by counting terminal buds every 24 hours. After 72 hours of culture, whole-mount CD31 immunostaining was performed.$^{30}$ Confocal z-stacks were imaged at $\times 100$ magnification, and a composite picture of the vasculature was generated using Photoshop CS5 software (Adobe Systems, San Jose, CA). Composites were skeletonized, and measurements of vascular patterning rel- ative to total explant surface area were calculated using ImageJ software.

\section{In Vitro Chemotaxis Assay}

Primary cultures of adult male rat pulmonary microvascular endothelial cells (PMVECs) were a gift from Dr. Judy Creighton (University of South Alabama Center for Lung Biology). Cells were grown in DMEM with $10 \%$ fetal bovine serum beginning at passage 9 and were used until passage 15. For cell chemotaxis, PMVECs were seeded to $5 \times 10^{6}$ in a T-75 flask and incubated for 36 hours to achieve $\sim 70 \%$ confluency. Cells were then serumstarved for 5 to 6 hours in DMEM, harvested using TrypLE Express enzyme (Invitrogen; Life Technologies), and resuspended in DMEM to $4 \times 10^{5}$ cells $/ \mathrm{mL}$.

Transwell inserts (24 wells, $8.0-\mu \mathrm{m}$ pore size) were coated with $5 \mu \mathrm{g} / \mathrm{mL}$ fibronectin (F4759; Sigma-Aldrich, St. Louis, MO) for 1 hour at $37^{\circ} \mathrm{C}$ and then rinsed. Next, $250 \mu \mathrm{L}$ of cell suspension ( $10^{5}$ cells total) was pipetted into the inner insert chamber, and $750 \mu \mathrm{L}$ of DMEM with chemoattractant was pipetted into the outer well. Inserts were incubated at $37^{\circ} \mathrm{C}$ for 22 hours, then rinsed in PBS and fixed with $4 \%$ paraformaldehyde. Nonmigrated cells (on the inner insert surface) were removed using a cotton swab, and migrated cells (on the outer insert surface) were stained with $0.6 \mu \mathrm{mol} / \mathrm{L} \mathrm{DAPI}$ and imaged using an inverted epifluorescence microscope; five random images at $\times 100$ magnification were captured for each insert. Images were uniformly thresholded, and particle analysis was performed in a batch to count nuclei using ImageJ software. The experiments (both conditioned medium-induced and individual factor-induced migration) were performed three times in triplicate with similar results.

Recombinant protein chemoattractants used were 50 $\mathrm{ng} / \mathrm{mL}$ human VEGF 165 and $500 \mathrm{ng} / \mathrm{mL}$ mouse Sema3c; $500 \mathrm{ng} / \mathrm{mL}$ mouse nerve growth factor receptor (Ngfr) 


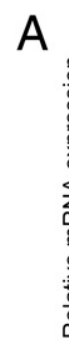

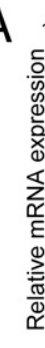
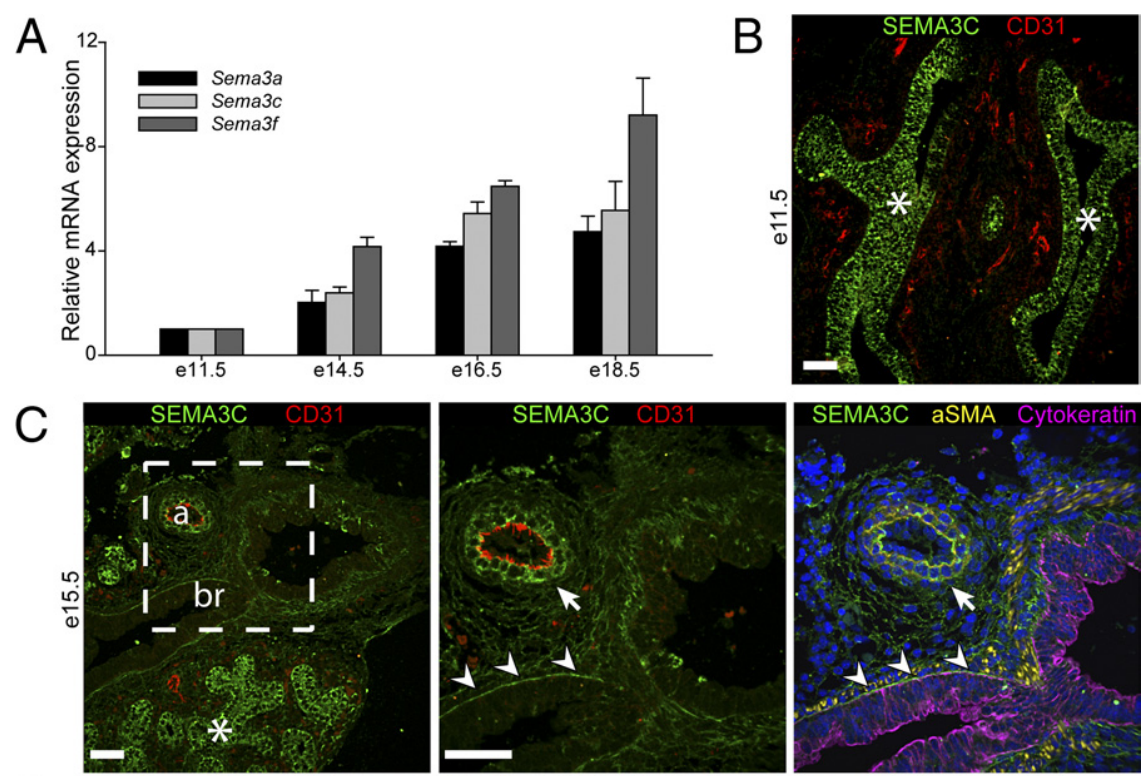

D
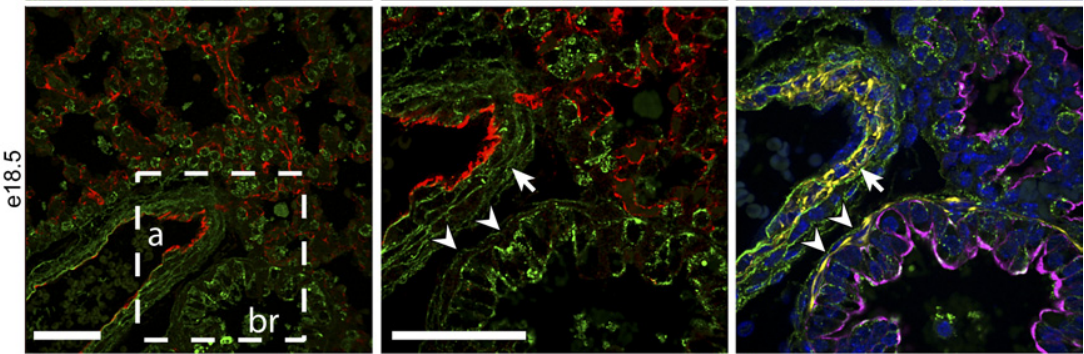

E
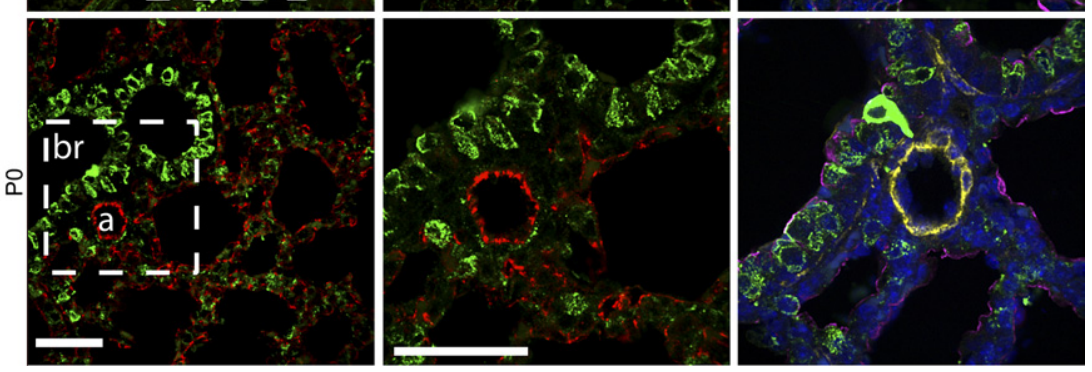

Figure 1. Sema3 expression during murine fetal lung development. A: qPCR analysis of prenatal lungs showed significantly increased expression of Sema3 ligands during prenatal lung development, relative to E11.5. B-E: Prenatal Sema3c protein expression (green) was examined by costaining the pulmonary epithelium for cytokeratin (pink), smooth muscle cells for $\alpha$-SMA (yellow), the vasculature for CD31 (red), and nuclei with DAPI counterstain (blue). By midgestation, strong Sema3c expression can be observed within the branching epithelium (asterisks) and along the abluminal surfaces of bronchiolar epithelium (arrowheads) by midgestation (B and $\mathbf{C}$ ). By late gestation and at birth, bronchiolar Sema3c expression became increasingly cellular, with diffuse staining within the septal walls of the saccular epithelium (D and E). Sema3c expression was also observed in $\alpha$-SMA-positive mural cells surrounding arterioles (arrows in $\mathbf{C}$ and $\mathbf{D}$ ) and diffusely within the peribronchiolar spaces before, but not after, birth $(\mathbf{C}-\mathbf{E})$. Boxed regions in the left panels (C-E) are shown at higher power in the middle panels; right panels show the equivalent region from a consecutive section, at the same magnification. Data are expressed as means \pm SEM. $P<0.05$, one-way analysis of variance. $n=3$ (except E11.5, which reflects one pooled litter). Scale bar $=50 \mu \mathrm{m}$. a, arteriole; br, bronchiole. was used as a negative control (all from R\&D Systems, Minneapolis, MN).

\section{Statistical Analysis}

Data are expressed as means \pm SEM. Student's unpaired $t$-test and one-way analysis of variance with HolmŠidák post-hoc analysis were performed using SigmaPlot version 11 software (Systat Software, San Jose, CA). $P<$ 0.05 was deemed statistically significant.

\section{Results}

\section{SEMA3 Ligand and Receptor Expression Increases during Fetal Lung Development}

Murine lung development begins at E9.5 and proceeds through defined stages that expand airway and vascular complexity and establish the epithelial-endothelial inter- face. For preliminary assessment of Sema3 signaling in these processes, gene expression of several Sema3 ligands and receptors in the fetal mouse lung was measured by qPCR (Figures $1 \mathrm{~A}$ and $2 \mathrm{~A}$ ). Large relative increases in expression were observed for all genes as gestation proceeded, particularly in gene expression of Nrp1, a critical receptor involved in vascular patterning throughout fetal development. ${ }^{19,31}$

We were particularly interested in the expression pattern of SEMA3C because, among other SEMA3 proteins, it is proangiogenic and is directly implicated in vascular morphogenesis. ${ }^{12,18,32,33}$ qPCR and immunocytochemistry on isolated late-gestation lung mesenchymal and epithelial cells demonstrated enrichments in Nrp1 and Sema3c $m R N A$, respectively, suggesting Sema3c-Nrp1 signaling interactions between the epithelium and endothelium during the formation of the alveolar-capillary interface (see Supplemental Figure S1 at http://ajp.amjpathol.org). 
A

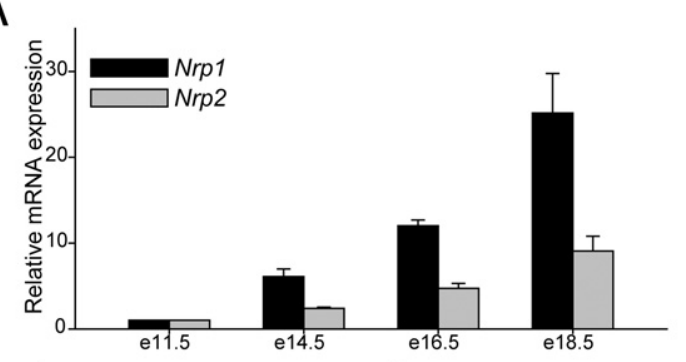

C

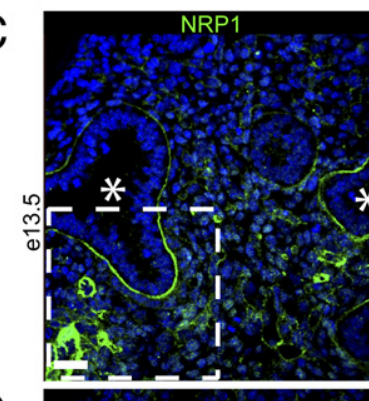

D

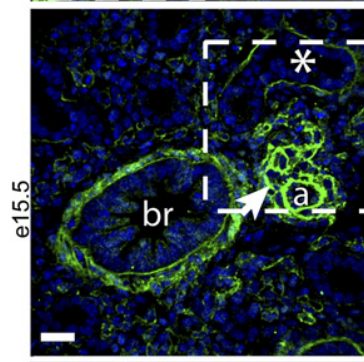

E
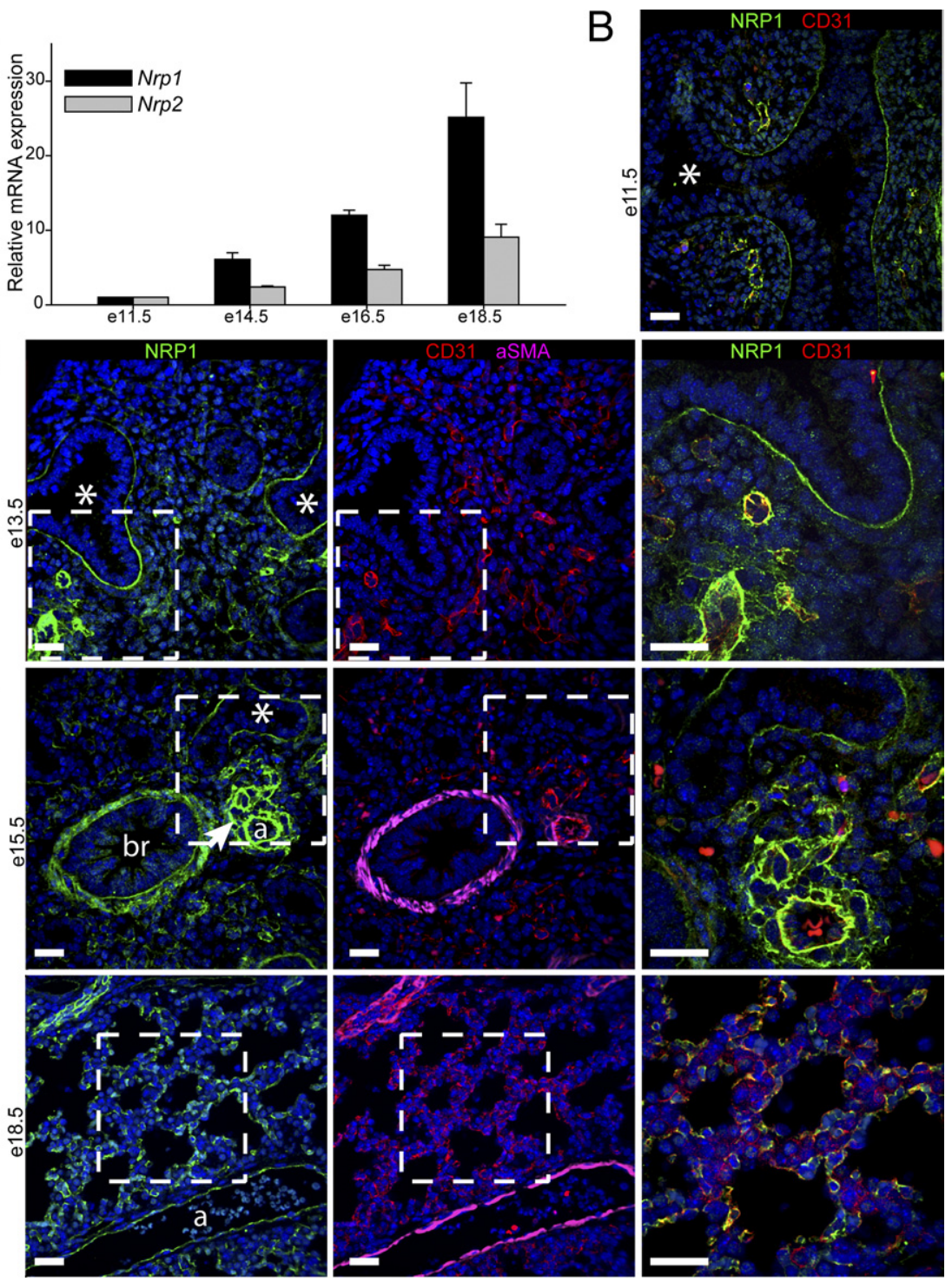

Figure 2. NRP1 expression during murine fetal lung development. A: qPCR analysis of prenatal lungs showed increased expression of the Nrp receptors, particularly Nrp1, relative to E11.5. B-E: NRP1 protein expression (green) was examined by costaining smooth muscle cells with $\alpha$-SMA (pink), the vasculature with CD31 (red), and DAPI nuclear stain (blue). NRP1 expression was observed along the abluminal edge of branching airway epithelium (asterisks, B-D), in mural cells surrounding arterioles (arrow in D), and throughout the pulmonary vasculature, including the developing capillary endothelium (E). Boxed regions in the left and middle panels $(\mathbf{C}-\mathbf{E})$ are shown merged and at higher power in the right panels. Data are expressed as means \pm SEM. $P<0.05$ one-way analysis of variance. $n=3$ (except E11.5, which reflects one pooled litter). Scale bar $=50 \mu \mathrm{m}$. a, arteriole; br, bronchiole.
In murine fetal lung sections, Sema3c protein was prominently expressed throughout the length of the branching airway epithelium at all stages of development (Figure 1, B-E). As gestation proceeded, Sema3c was also secreted along the abluminal edge of the bronchiolar epithelium (Figure 1, B and C) and in the distal epithelium, which forms the epithelial component of the alveolar-capillary interface (Figure 1, D and E). Sema3c was also distinctly expressed in $\alpha$-smooth muscle actin ( $\alpha$-SMA)-positive mural cells surrounding arterioles, and diffusely expressed in the peribronchiolar adventitia, although it was conspicuously absent from the pulmonary endothelium (Figure 1, D and E).

Nrp1 protein was clearly detectable along the abluminal border of the airway epithelium and surrounding mural cells of pulmonary vessels (Figure 2, B-D), similar to Sema3c, as well as throughout the developing vascular endothelium. Nrp1 was also present in capillary endothelium as the microvasculature formed the endothelial-epithelial interface during the later stages of saccular development (Figure 2E). In contrast, Nrp2 protein was restricted to the airway epithelium (see Supplemental Figure S2 at http://ajp.amjpathol.org).

\section{Loss of Sema3-Nrp1 Signaling Causes}

Respiratory Distress, Vascular Abnormalities, and Postnatal Lethality

The similar expression patterns of Sema3c and Nrp1 in the branching epithelium are in accord with their known involvement in lung branching morphogenesis. ${ }^{9}$ However, the temporal and complementary patterns of Sema3c and Nrp1 in the fetal pulmonary epithelium and endothelium, respectively, suggested an interaction during the early formation of the bronchovascular bundles and the later development of the alveolar-capillary interface.

We sought to determine whether Sema3-Nrp1 interactions in isolation are critical for fetal respiratory development. Accordingly, we obtained Nrp1 $1^{\text {Sema- }}$ transgenic mice, which have a small Nrp1 mutation that prevents 

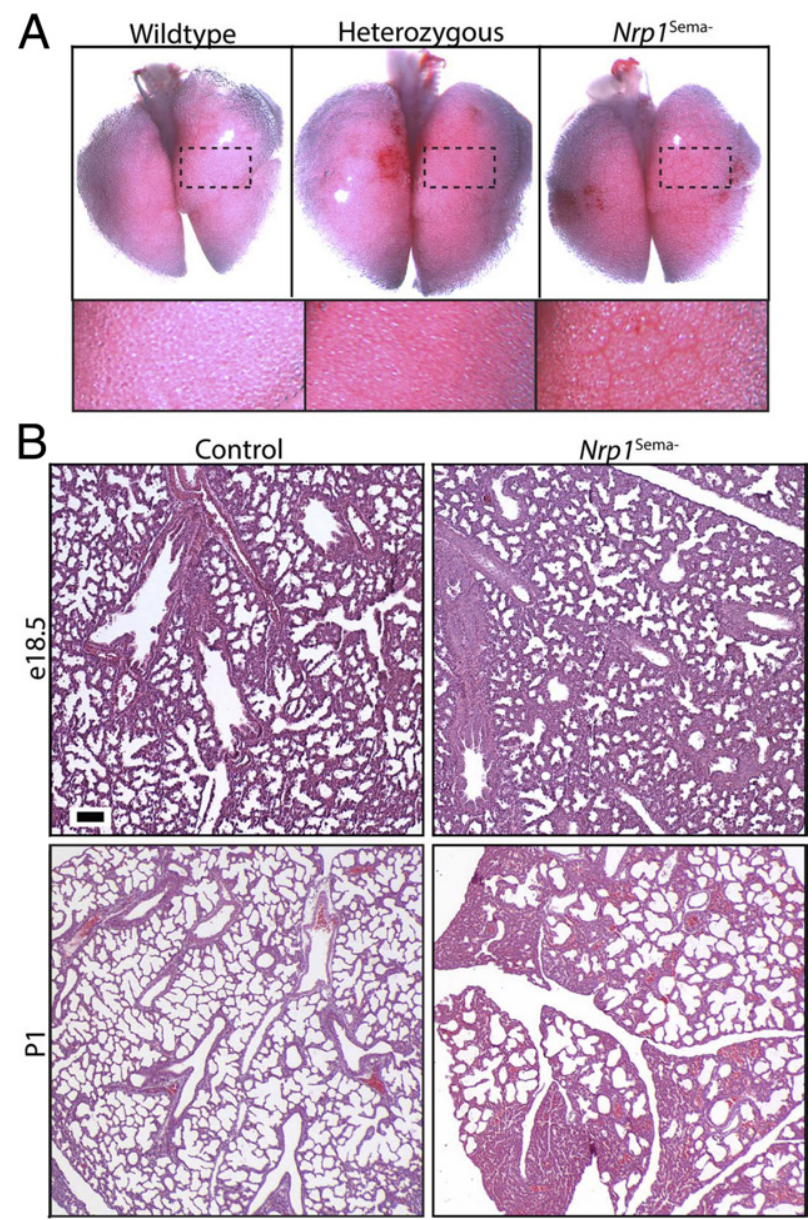

Figure 3. Lung morphology of control and $N_{r p} 1^{\text {Sema- }}$ neonates. A: Wildtype, heterozygous, and homozygous mutants were grossly normal at P1; however, interlobular septa were more pronounced in mutants, compared with controls. Boxed regions are shown at higher power below each image. B: H\&E-stained lungs at E18.5 and P1. Moderate thickening of saccules was observed in mutants, compared with controls, at E18.5. At P1, mutants display vast atelectatic regions, rounded and more simplified saccular spaces, and thickened alveolar interstitium. Scale bar $=50 \mu \mathrm{m}(\mathbf{B})$; original magnification, $\times 5$ (A).

Sema3-Nrp1 binding but leaves Vegf-Nrp1 interactions intact. $^{19}$ Our initial observation was that, although Nrp1 ${ }^{\text {Sema- }}$ homozygous pups were born at the expected Mendelian ratios, neonatal lethality was substantially higher than previously reported. ${ }^{19}$ Lethality within the first $\sim 12$ hours of birth was only $2.3 \%$, but dramatically increased to $56.3 \%$ within $\sim 36$ hours postnatal (see Supplemental Figure S3 at http://ajp.amjpathol.org). Newborn Nrp $1^{\text {Sema- }}$ homozygotes tended to be cyanotic and less ambulatory than wild-type or heterozygous littermates (see Supplemental Figure S3 at http://ajp.amjpathol.org). Of 14 mice in this sample set observed beyond 36 hours, only 6 lived beyond P4, although in general survivors were rare and noticeably smaller than control littermates. No overt differences were observed between heterozygous and wild-type mice.

To determine whether the presenting phenotype was due to acute respiratory distress, we examined the lungs of $\mathrm{Nrp} 1^{\text {Sema- }}$ mutant and control mice. On gross inspection at postnatal day 1 (P1), interlobular septa were more prominent (Figure 3A). Histological examination at E18.5 revealed subtle differences, including thicker, rounder, and more simplified developing saccules in Nrp1 $1^{\text {Sema- }}$ mutants, compared with controls (Figure 3B). By P1, control lungs underwent further thinning and increased in structural complexity, whereas Nrp1 ${ }^{\text {Sema- }}$ mutant saccules remained dilated and septal walls remained thickened and unremodeled (Figure 3B). This was reflected in an increased parenchymal tissue:airspace distribution $\left(62.3 \pm 2.9 \%\right.$ versus $43.2 \pm 4.9 \%, N r p 1^{\text {Sema }-}$ and control, respectively; $P=0.015, n=4$ ), although parenchymal cell proliferation, as assessed by Ki-67 expression, remained low in both cohorts (1.96 $\pm 0.20 \%$ for Nrp1 $1^{\text {Sema- }}$ versus $2.13 \pm 0.21 \%$ for control; $P=0.62$, $n=4$ ), indicating that saccular thickness in mutants was not due to increased cell proliferation. Notably, broad atelectatic regions in $\mathrm{Nrp} 1^{\text {Sema- }}$ homozygotes were present and generally localized to the lung periphery, likely contributing to the observed hypoxemia and high lethality (Figure 3B).

Closer inspection revealed focal areas sharing characteristics of clinical ACD, including close association of ectatic veins with arterioles and pulmonary hypertensive changes (Figure 4A). Interestingly, supernumerary capillaries embedded within the peribronchiolar spaces were also observed in mutants (Figure 4A; see also Supplemental Figure S3 at http://ajp.amjpathol.org). In five litters, seven mutant samples were observed by two investigators masked to genotype: five mutants displayed abnor-

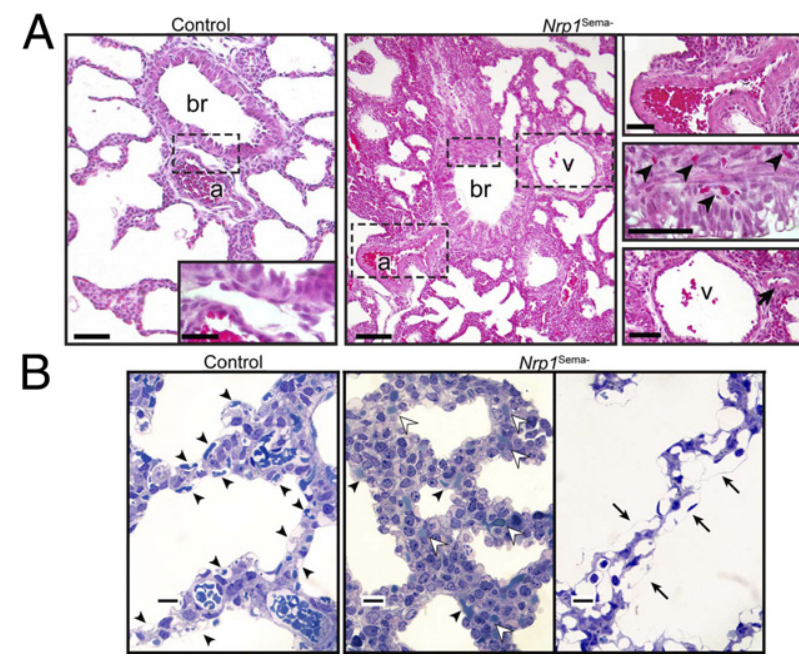

Figure 4. $N r p 1^{\text {Sema- }}$ mutants present with focal areas of pronounced vascular anomalies. A: In a control animal at P1 (left panel), lung at the periphery shows a typical bronchiole-arteriole association in the peribronchiolar space; the thinness of the arteriolar smooth muscle layer is typical for newborn mice. The boxed region is shown at higher power in the inset. In contrast, $N r p 1^{\text {Sema- }}$ littermates (middle and right panels) present with various abnormalities, including marked thickening and muscularization of arterioles ectopic capillaries within the peribronchiolar space (arrowheads), and ectatic veins in close association with arterioles (arrow). The three boxed regions in the middle panel are shown at higher power at the right. B: Toluidine blue-stained lungs at P1. Numerous capillaries lining the alveolar wall (black arrowheads) were observed in control mice (left). In similar fields from an $\mathrm{Nrp}^{\mathrm{Sema}}{ }^{-}$mouse (middle and right), normal capillaries lining the epithelium were rare; instead, capillaries were frequently found within septa (white arrowheads) or were abnormally dilated (arrows). Scale bars: $100 \mu \mathrm{m}$ (A, left and middle panels); $25 \mu \mathrm{m}$ (A, inset in left panel; A, three images in right panel); $10 \mu \mathrm{m}$ (B). a, arteriole; br, bronchiole; v, venule. 
mal peribronchiolar vascular phenotypes, with the remaining two displaying mild hypertensive changes; none of the six wild-type littermates displayed any abnormality. In addition, Nrp1 ${ }^{\text {Sema- }}$ mutants frequently lacked capillaries in the saccular interstitium surrounding terminal bronchioles with malformed vasculature, and in general had fewer but larger capillaries in the interstitial walls of enlarged saccules (Figure 4B). Capillaries were frequently embedded within the center of the septal interstitium, suggesting poor development of the capillary-alveolar interface (Figure 4B). These findings were recapitulated by ultrastructural analysis using TEM (Figure 5).

\section{Impaired Pulmonary Angiogenesis in Nrp1 ${ }^{\text {Sema- }}$ Mice}

Because class 3 semaphorins have been proposed as mediators of vascular development, ${ }^{12,14}$ we further assessed the microvasculature in $\mathrm{Nrp} 1^{\mathrm{Sema}-}$ mutants. Morphometric analyses revealed significantly reduced numbers and increased dilation of capillaries within the alveolar walls in $\mathrm{Nrp} 1^{\mathrm{Sema}-}$ mice relative to controls (Figure 6, A and B). Decreased microvascular arborization was recapitulated using fluorescent microangiography of the pulmonary circulation, in which poor capillary perfusion was observed in the majority of $\mathrm{Nrp} 1^{\text {Sema- }}$ mutants examined (4 of 7 mutants, 0 of 4 controls) (Figure 6C).

During mid to late embryonic lung morphogenesis, the developing microvasculature begins vessel ingrowth into the parenchymal interstitium, forming in close apposition to the epithelium. CD31 immunostaining appeared to show a general reduction in vascular complexity during this process in $\mathrm{Nrp} 1^{\text {Sema- }}$ mutants at E16.5, although when quantified relative to epithelial cytokeratin expression this difference was not statistically significant (Figure 7A). Sema3c and Nrp1 expression patterns did not appear to be affected in E16.5 Nrp1 ${ }^{\text {Sema- }}$ mice (see Supplemental Figure S4 at http://ajp.amjpathol.org). After birth, whereas control mice featured endothelial cells lining the parenchymal epithelium to form the air-blood

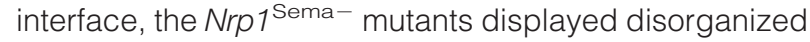
regions of endothelial cells embedded within the saccular walls (Figure 7B). Moreover, the pattern of erythrocytes in the developing saccular walls appeared disorganized and not in close apposition with the epithelial lining as observed in control littermates (Figures 4B and $7 \mathrm{~B})$, indicative of aberrant vessel patency.

qPCR was used to determine whether the pathohistological defects observed in mutant neonates could be explained by altered expression of genes involved in normal alveolar development. Interestingly, no significant differences were observed in genes involved in type I or type II pneumocyte function or in the angiopoietin-Tie2 or Sema3c-Nrp1 pathways (see Supplemental Figure S5 at http://ajp.amjpathol.org). In contrast, significant decreases in expression of total Vegf transcripts, the Vegf $_{188}$ isoform, and the canonical VEGF receptor Vegfr2 were observed in the mutants (Figure 7C). Reduction in Vegfr2 protein was confirmed by immunoblotting, although CD31 levels remained unchanged (Figure 7D).
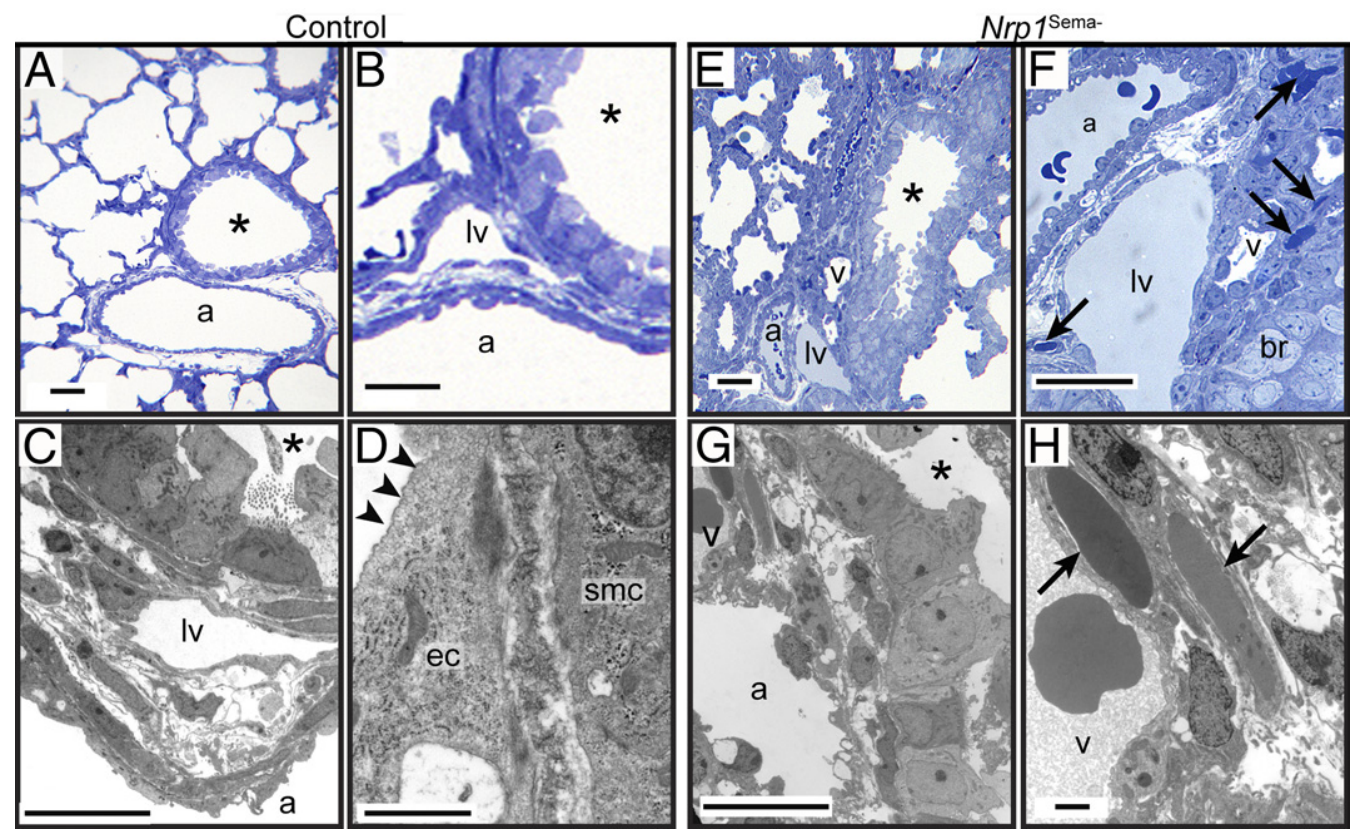

Figure 5. Peribronchiolar ultrastructure in control (A-D) and mutant (E-H) animals at P1. A-D: Photomicrographs of toluidine blue-stained sections at low (A) and high (B) power from a control animal show the lumen of a normal terminal bronchiole (asterisk), lymphatic vessel (lv), and arteriole (a). TEM images from the same region are also shown, at low (C) and high (D) power reveal numerous pinocytotic vesicles (arrowheads), an endothelial cell (ec), and a layer of loose fibrillar material between the endothelial cell and smooth muscle cell (smc), typical for newborn mice. E-H: In contrast, photomicrographs of sections from $N r p 1^{\text {Sema- }}$ mice at low (E) and high (F) power show numerous vessels within the peribronchiolar space, including an arteriole, lymphatic vessel, vein (v), and ectopic capillaries (arrows); bronchiolar epithelium (br) is also indicated. TEM images from a similar area at low (G) and high (H) power reveal an arteriole and venule occupying the same peribronchiolar space with ectopic capillaries (arrows). The arteriolar endothelial cells appear rounded up and contain cytoplasmic vacuoles $(\mathbf{G})$. Scale bars: $25 \mu \mathrm{m}(\mathbf{A}, \mathbf{B}, \mathbf{E}$, and $\mathbf{F}) ; 10 \mu \mathrm{m}(\mathbf{C}$ and $\mathbf{G}) ; 1 \mu \mathrm{m}(\mathbf{D}$ and $\mathbf{H})$ 
A

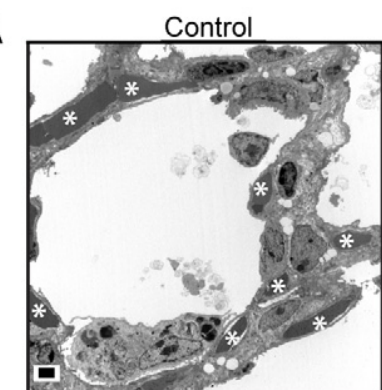

B
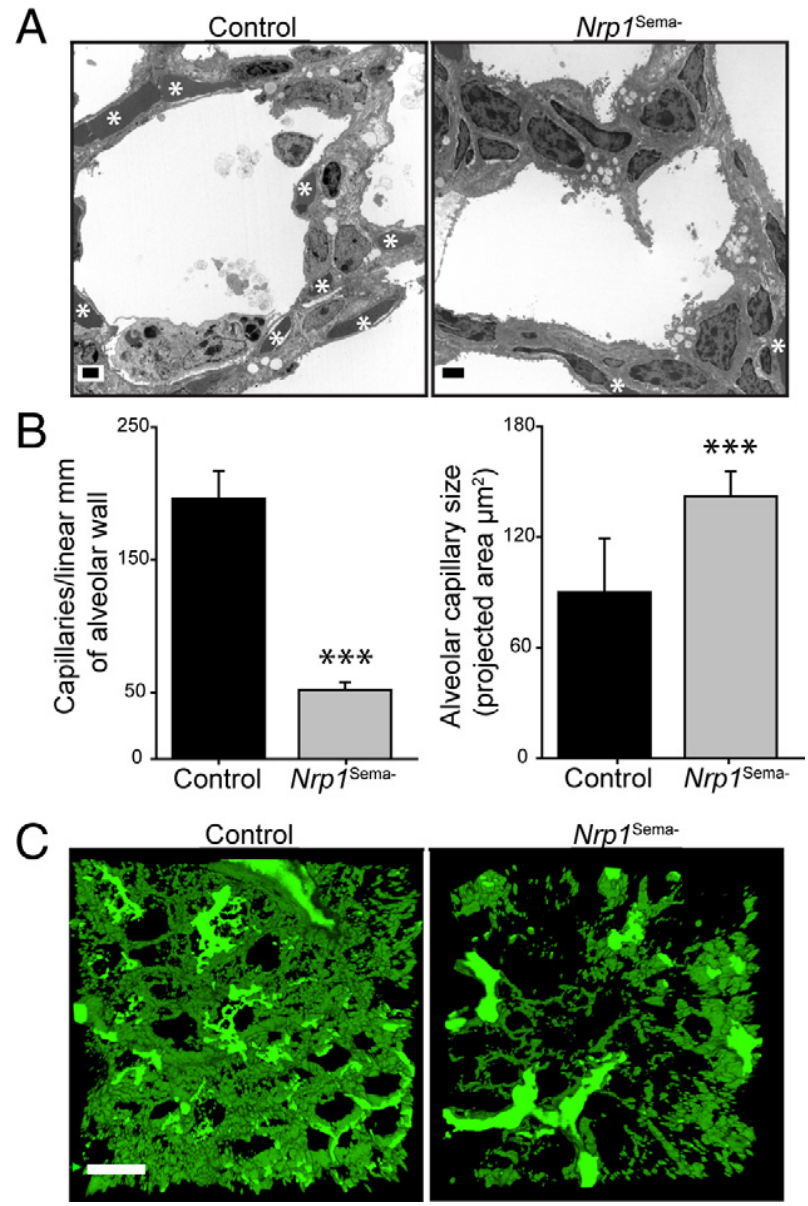

Figure 6. Reduced pulmonary microvascular patency in $N r p 1^{\mathrm{Sema}-}$ mice at P1. A: TEM in P1 control mice showed an organized capillary network (asterisks). In contrast, the septal interstitium of $N r p 1^{\mathrm{Sema}-}$ mutants was thickened, with few capillaries present. B: Quantification of decreased microvascularization and increased capillary dilation in the saccular walls of $N r p 1^{\text {Sema- }}$ mutants relative to controls. C: Pulmonary fluorescent microvascular angiography revealed an organized capillary network in control mice, whereas in $N r p 1^{\mathrm{Sema-}}$ mutant mice it revealed large avascular regions in 4 of 7 mice examined. ${ }^{* * * *} P<0.001 . n=100$ fields from 2 animals per group. Scale bars: $2 \mu \mathrm{m}(\mathbf{A}) ; 100 \mu \mathrm{m}(\mathbf{C})$.

Because mutations in the Foxf1 and Nos3 (eNOS) genes have been implicated in experimental or clinical ACD, ${ }^{8,34,35}$ transcript levels were measured in Nrp $1^{\text {Sema- }}$ mutants by qPCR. Reduced expression was observed in both genes, although only Foxf1 transcript levels reached statistical significance (Figure 7C).

Because the pulmonary vasculature develops in congruence with airway branching during fetal lung morphogenesis, we were interested in whether the perinatal phenotype of $\mathrm{Nrp} 1^{\text {Sema- }}$ mutants originates from morphogenetic defects arising during early airway branching. We therefore assessed fetal airway and circulatory development using cultured E11.5 lung explants. We observed that ex vivo lung branching proceeded normally in both Nrp $1^{\text {Sema- }}$ mutant and control mice, whereas the developing pulmonary vascular plexus appeared normal, as assessed by skeletonized morphometry on CD31-stained whole-mount explants (see Supplemental Figure S6 at http://ajp.amjpathol.org). This finding suggests that the aberrant vessel patency postnatally does not stem from defects in airway branching morphogenesis or very early vascular plexus organization.

\section{Sema3c Has Promigratory Effects in Vitro}

To assess whether Sema3-Nrp1 signaling is involved in the expansion of the fetal pulmonary vasculature, in vitro chemotactic experiments were conducted on primary cultures of rat PMVECs, ${ }^{36}$ which endogenously express Nrp1 (Figure 8A). PMVECs seeded onto fibronectin-coated Transwell inserts strongly migrated in response to conditioned medium (CM) isolated from primary cultures of E19 rat pulmonary epithelial cells (Figure $8 \mathrm{~B}$ ). Notably, no migratory response was observed when PMVECs were incubated with E19 rat pulmonary mesenchymal CM. Secreted Sema3c protein was strongly detected in epithelial CM, whereas the soluble Nrp1 isoform (sNrp1), an endogenously encoded VEGF and SEMA3 antagonist, ${ }^{37}$ was found exclusively in mesenchymal CM (Figure 8B).

To determine whether Sema3c influences endothelial cell migration, PMVECs were seeded onto Transwell inserts and exposed to either recombinant human VEGF or murine Sema3c. In both cases, PMVEC migration was significantly enhanced in response to treatment (Figure 8C), although 10-fold higher concentrations of Sema3c relative to VEGF were required to elicit an equivalent response.

\section{Potentially Abnormal Vascular Integrity in Nrp1 ${ }^{\text {Sema- }}$ Mice Due to Structural Instability}

Mural cells are essential supportive cells for vascular development and homeostasis. ${ }^{38}$ Mural cells include $\alpha$-SMA-positive and NG2-positive vascular smooth muscle cells (vSMCs), which form multiple concentric layers surrounding arteries and veins, and also pericytes, which are NG2-positive but $\alpha$-SMA-negative and form a discontinuous association with the pulmonary microvasculature. ${ }^{39,40}$ Because we noted expression of both Sema3c and Nrp1 protein in vSMCs surrounding arterioles (Figures $1 \mathrm{C}$ and 2D), we wondered whether loss of Sema3Nrp1 signaling would cause mural cell dysfunction. Interestingly, large pulmonary arterioles and venules in mutant and control mice appeared to be intact and surrounded by supportive vSMCs, as assessed by immunostaining (Figure 9A). Moreover, pericytes were still associated with the abnormal capillary microvasculature of Nrp $1^{\text {Sema- }}$ mutants, suggesting typical mural cell recruitment to the endothelium (Figure 9A). However, ultrastructural examination of these tissues demonstrated significantly reduced numbers of vSMCs associated with large pulmonary vessels in Nrp1 $1^{\text {Sema- }}$ mutants (Figure 9B). Furthermore, microvascular endothelial-epithelial attachment at the shared basal lamina was significantly reduced in Nrp1 ${ }^{\text {Sema- }}$ mutants, suggesting alveolar-capillary barrier immaturity and poor mechanical stability of the endothelium (Figure 9C).

Alveolar myofibroblasts are essential smooth muscle cells recruited to the saccular interstitium, whereupon they promote alveolar septal formation. ${ }^{41}$ In accord with 
A
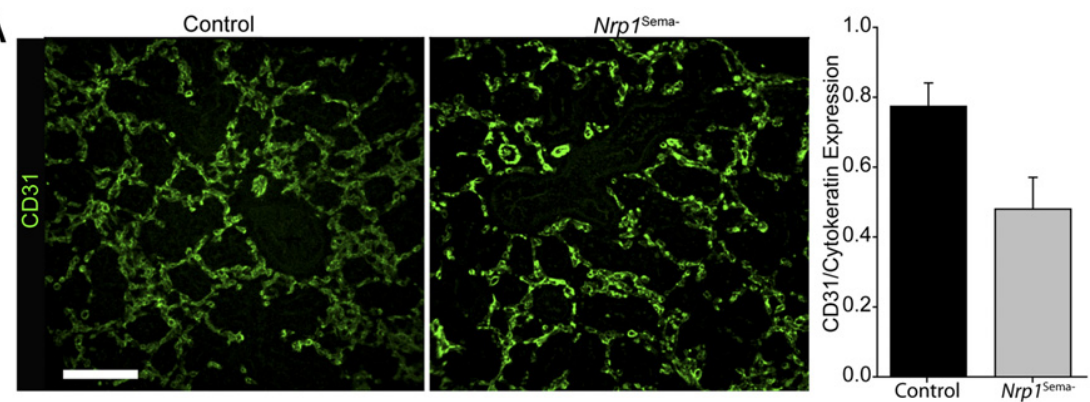

B

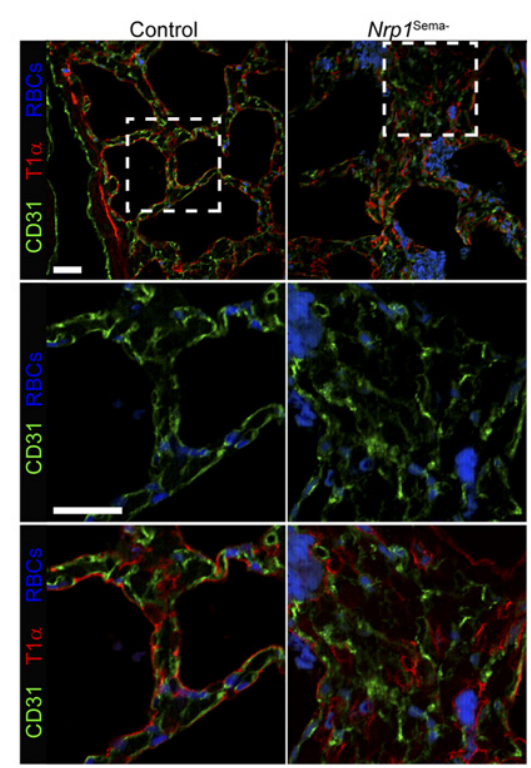

C 홀
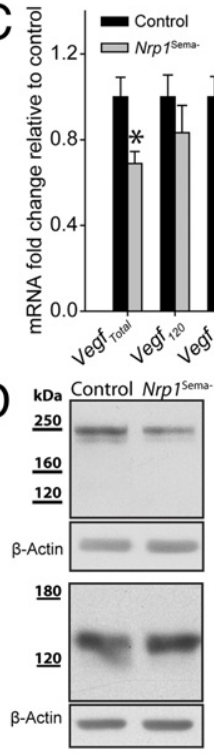

0.04

$\mathrm{Nrp} 1^{\text {Sema- }}$

Figure 7. Abnormal microvascular patterning in $N r p 1^{\text {sema- }}$ mice at P1. A: CD31 immunostaining at E16.5 showed an apparent reduction in capillary density in $N r p 1^{\text {Sema- }}$ mutants; however, quantification of CD31 expression relative to epithelially expressed cytokeratin indicated no significant difference $(P=0.060)$. B: CD31 immunostaining (green) in control mice revealed endothelial cells in close association with the type I epithelium (immunostained red with $\mathrm{T} 1 \alpha$ ). In contrast, endothelial cells appeared largely disorganized within the interstitium in $\mathrm{Nrp}^{\mathrm{Sema}-}$ mice. Autofluorescent erythrocytes are pseudocolored blue. Boxed regions in the top row are shown at higher power in the middle and bottom rows. C: Expression of total Vegf, Vegf 188 , Vegfr2, and Foxf1 mRNA was significantly reduced in $\mathrm{Nrpl}^{\mathrm{Sema}-}$ mutants, compared with controls. D: Representative immunoblots and densitometry data for VEGFR-2 and CD31. Significantly decreased expression of VEGFR-2 (but not CD31) in $N r p 1^{\text {Sema- }}$ mutants was quantified relative to $\beta$-actin. ${ }^{*} P<0.05 . n=$ 3 (A); $n \geq 4$ (C); $n=6$ (D). Scale bars: $100 \mu \mathrm{m}$ (A); $25 \mu \mathrm{m}$ (B). OD, optical density.

arrested alveolar development, there was a conspicuous absence of $\alpha$-SMA-positive myofibroblasts at the sites of presumptive septal tips and a lack of $\alpha$-SMA-positive smooth muscle cells distributed within the saccular interstitium of mutant mice (Figure 9A).

\section{Pulmonary Surfactant Deficiency in $\mathrm{Nrp}^{\mathrm{Sema}-}$ Neonates}

To determine the cause of the atelectasis observed in P1

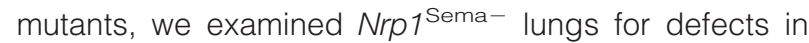
surfactant production. Pulmonary surfactant is synthesized and secreted by alveolar type II cells to prevent alveolar collapse postnatally. ${ }^{42}$ Expression of the type II cell marker proSPC did not differ between mutants and controls, as quantified by immunostaining (20.0 $\pm 4.9 \%$ for Nrp1 $1^{\text {Sema- }}$ versus $19.4 \pm 2.7 \%$ for control; $P=0.92$, $n=4$ ) (Figure 10A) or by qPCR (see Supplemental Figure S5 at http://ajp.amjpathol.org). Under TEM, lamellar bodycontaining type II pneumocytes were morphologically distinguishable in $\mathrm{Nrp}^{\text {Sema- }}$ mutants, but were significantly fewer in number, relative to controls. Moreover, the characteristic phospholipid whorls within the surfactantcontaining lamellar bodies were often malformed or completely absent, suggesting decreased surfactant synthesis (Figure 10, B and C). Phosphatidylcholines (PCs), particularly the dipalmitoyl-PC (DPPC) species, are es- sential phospholipid components of surfactant. ${ }^{43}$ Mass spectroscopic analysis of bronchoalveolar lavage fluid from P1 mutants showed significantly decreased secretion of total PCs and DPPC (Figure 10D), confirming that surfactant deficiency contributed to alveolar collapse in Nrp1 $1^{\text {Sema- }}$ mice. However, no aberrant expression of essential proteins involved in surfactant synthesis or lamellar body packaging ${ }^{42}$ was observed (Figure 10E; see also Supplemental Figure S5 at http://ajp.amjpathol.org).

\section{Discussion}

Herein, we describe the critical importance of Sema3Nrp1 signaling in fetal lung development. In a previous study of Nrp $1^{\text {Sema- }}$ mice, lethality after several days of postnatal life was reported, but no cause of mortality was established, ${ }^{19}$ leading us to hypothesize a failure of postnatal microvascular maturation as the cause of death. In the present study, however, we observed substantial lethality by $\mathrm{P} 1$, suggesting instead a defect encountered during fetal development. Indeed, the temporospatial expression pattern of Sema3c and Nrp1 implicated the involvement of Sema3-Nrp1 interactions in the development of the peribronchiolar vessels and the alveolarcapillary interface. Profound lung defects in Nrp1 $1^{\text {Sema- }}$ mice resembling pathological features of clinical $A C D$ were observed, including reduced capillary density, fail- 


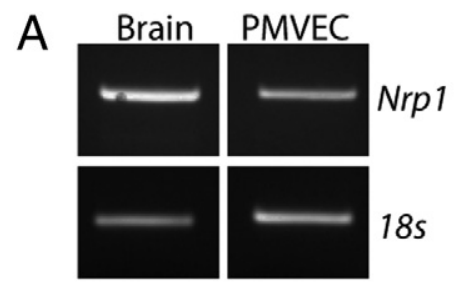

Figure 8. PMVEC migratory behavior. A: RT-PCR shows that PMVECs express Nrp1. Neonatal mouse brain was used a positive control. B: PMVECs migrate dose-dependently in response to CM from cultured E19 rat lung epithelial cells (Ep $\mathrm{CM}$ ), but not to CM from E19 rat lung mesenchymal cells (Mes CM) (left panel); quantification (middle panel) reveals the dose dependence. Concentrated epithelial and mesenchymal CM ( $5 \mu \mathrm{g}$ each) was serially probed for Sema3c and sNRP1 (right panel). Coomassie staining of the gel was performed after transfer to polyvinylidene difluoride membrane to demonstrate equal loading. C: PMVECs migrate in response to $50 \mathrm{ng} / \mathrm{mL} \mathrm{VEGF}_{165}$ and $500 \mathrm{ng} / \mathrm{mL} \mathrm{Sema3c.}{ }^{*} P<0.05 . n=$ 3 per condition.
$\mathrm{B}$
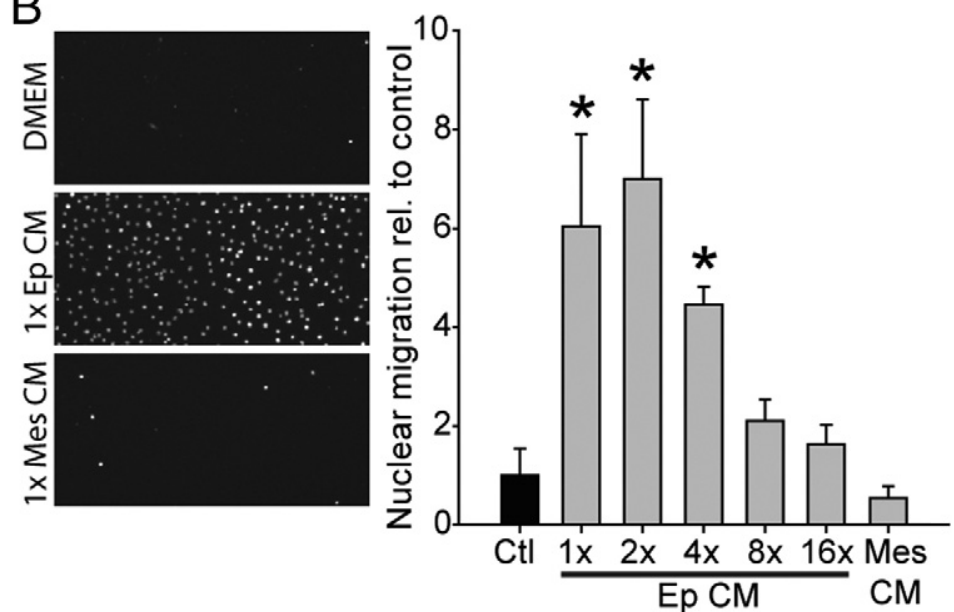
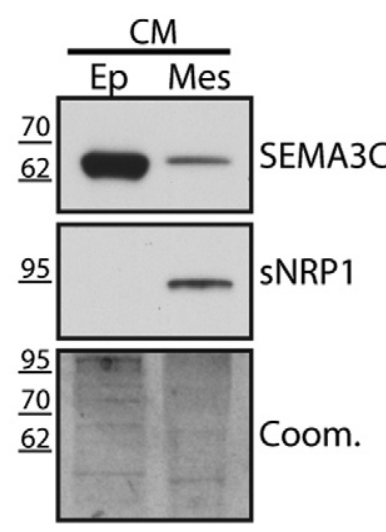
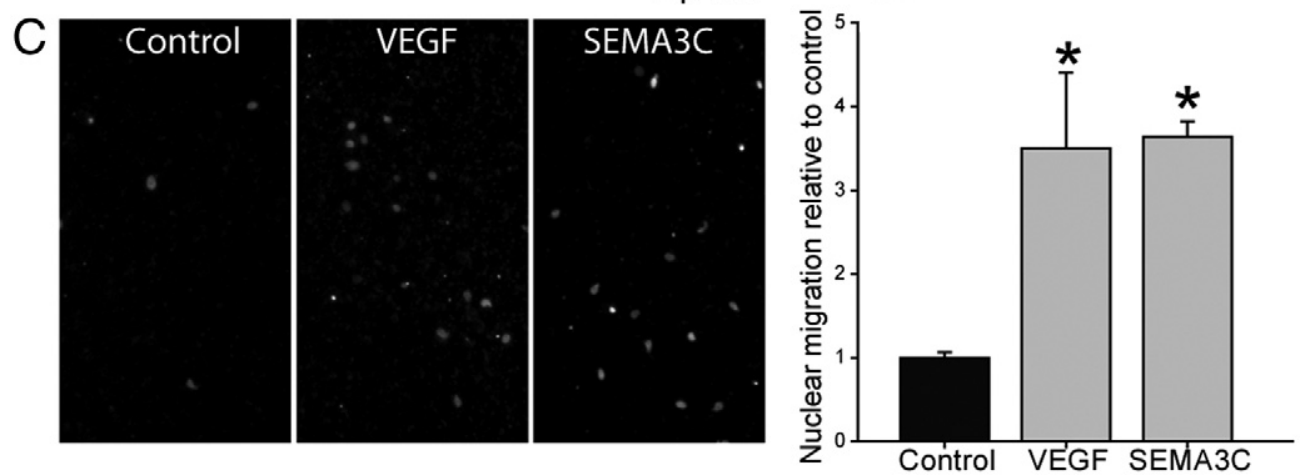

ure of alveolar-capillary interface formation, misaligned and ectatic pulmonary veins, reduced surfactant production, and ultimately respiratory distress contributing to neonatal mortality. Contrary to previous reports, ${ }^{19,22}$ the present study provides strong evidence of the involvement of Sema3-Nrp1 signaling in essential aspects of vascular development.

During early development, the pulmonary vasculature forms patent vessels within the splanchnopleural mesenchyme by angiogenic sprouting in concert with epithelial branching. ${ }^{44}$ Loss of Sema3-Nrp1 signaling did not affect these processes in cultured E11.5 explants, because vessel formation and lung branching largely occur independently before E14.5, ${ }^{27,44}$ although mutual prosurvival signaling maintains these tissues. ${ }^{45}$ Moreover, redundant SEMA3-NRP2 signaling may be sufficient for branching morphogenesis, particularly given the strongly localized expression of NRP2 in the epithelium. However, during later embryonic stages, the mesenchymally embedded vascular plexus expands and extends toward the epithelial-mesenchymal junction as a response to secreted factors originating from the basilar epithelium, and the alve- olar-capillary interface is ultimately formed by basal membrane fusion. ${ }^{44}$ The other NRP1 ligand, VEGF, is an essential chemoattractant in this process. An ACD-like phenotype has been described in mice deficient for VEGF or for its upstream activator, eNOS. ${ }^{8,46}$ In the same way, the inability of Nrp1-expressing endothelial cells to respond to epithelially derived Sema3 signals may have restricted the expansion of the vascular plexus toward the epithelium and prevented membrane fusion and interface formation at this later stage of development, particularly in light of well-described promigratory Sema3Nrp1 functions on endothelial cells. ${ }^{14,32,33}$

Our observations of PMVEC migration in response to both Sema3c-enriched epithelial CM and isolated Sema3c protein support this paradigm. We observed apparently reduced vascular density in $\mathrm{Nrp}^{\text {Sema- }}{ }^{\text {mice }}$ at E16.5, although at this time point the decrease was not yet statistically significant. Defects in endothelial guidance and vessel maturation after this time point could therefore have culminated in the severely reduced capillary density, centralized placement of capillaries within septa, and reduced capillary-pneumocyte membrane 

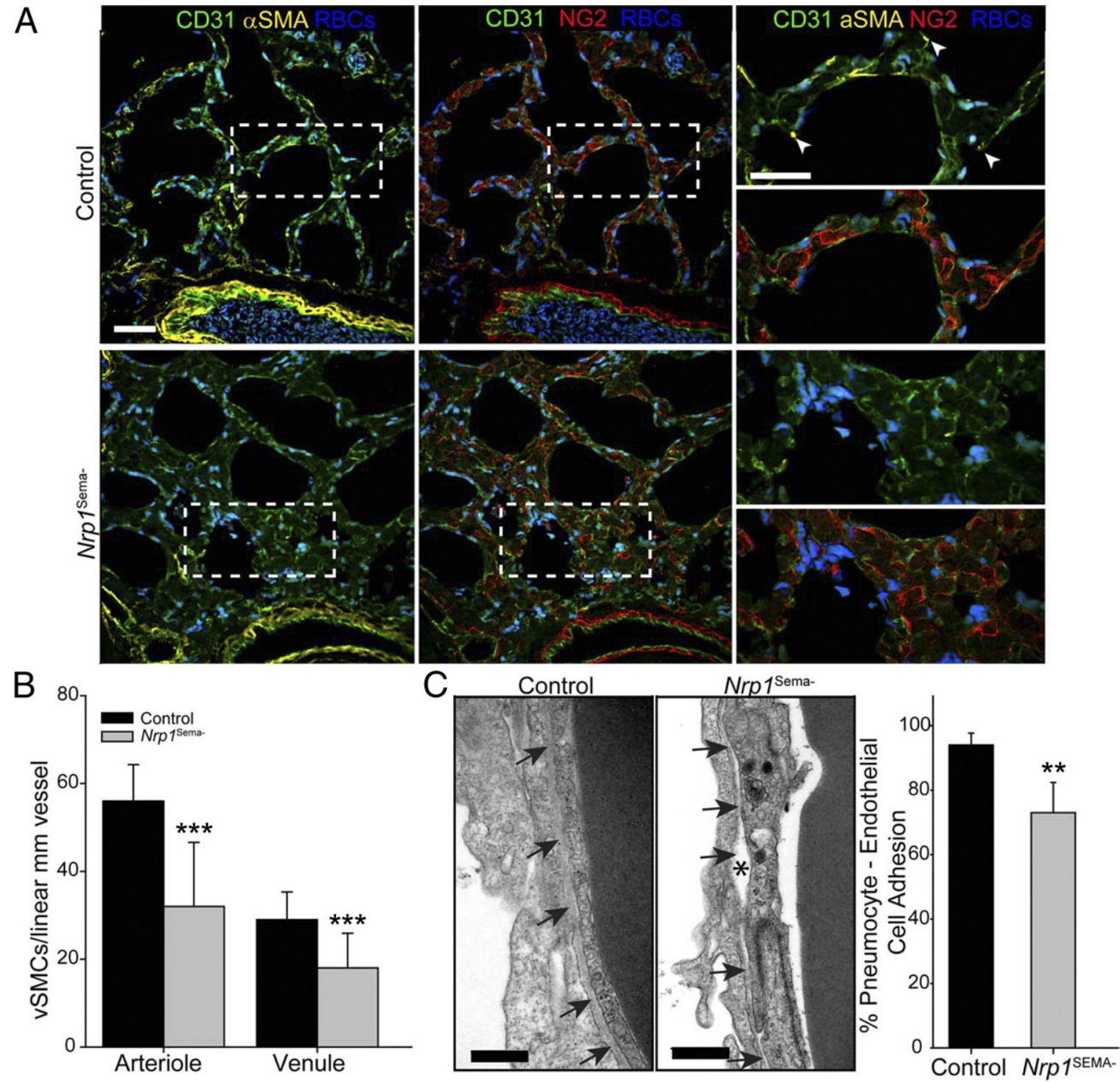

Figure 9. vSMC and pericyte association in $N r p 1^{\text {Sema- }}$ mice at P1. A: Lungs at P1 were tripled-stained for CD31 and the vSMC/pericyte markers $\alpha$-SMA and NG2. $\alpha$-SMA-positive and NG2-positive vSMCs appeared to surround arterioles and venules in both cohorts. However, $\alpha$-SMA-positive myofibroblasts at developing septal tips (arrowheads) were common in control but not mutant lungs. NG2-positive interstitial pericytes were still associated with the abnormal capillary microvasculature of $\mathrm{Nrp1}^{\text {Sema- }}$ mice. Boxed regions (left and middle panels) are shown at higher power at the right panel. Autofluorescent erythrocytes are pseudocolored blue. B: The number of vSMCs per linear millimeter of vessel was counted. vSMC association with arterioles and venules was significantly reduced in $N r p 1^{\text {Sema- }}$ mutants, compared with controls. C: Representative TEM image indicating pneumocyte-endothelial cell detachment (asterisk) from the basal lamina (arrows) in $N r p 1^{\text {Sema- }}$ mice. The percentage of type I pneumocyte-endothelial cells in contact with the basal lamina was reduced $(P=0.007)$ in mutants. ${ }^{* *} P<0.01 ;$ ${ }_{* * * * *} P<$ 0.001. $n=2$ animals per group $(\mathbf{B}) ; n=50$ fields from 2 animals per group (C). Scale bars: $50 \mu \mathrm{m}(\mathbf{A}) ; 500 \mathrm{~nm}(\mathbf{C})$.

adhesion observed in Nrp1 $1^{\text {Sema- }}$ neonates. It is not clear whether the presenting phenotype resulted from the absence of unique Sema3-Nrp1 signaling mechanisms, ${ }^{12}$ unregulated Vegf-Nrp1 binding, ${ }^{47}$ or through alterations in the formation of Nrp1-Vegfr-2 complexes. ${ }^{15}$

One important limitation of the present study is the difficulty in isolating the precise mechanism behind the dysmorphic vasculature of $\mathrm{Nrp} 1^{\mathrm{Sema}-}$ mice. Because reciprocal epithelial-endothelial cell interactions are essential during lung morphogenesis, ${ }^{27,46}$ the congenital nature of the $\mathrm{Nrp1}^{\mathrm{Sema}-}$ mutation precludes the unambiguous identification of Sema3-Nrp1 signaling as a direct mediator of pulmonary angiogenesis per se. That is, despite the clear histological evidence of aberrant alveolar-capillary interface formation and microvascular attenuation in Nrp1 ${ }^{\text {Sema- }}$ mutants, it is not clear whether this resulted from a primary defect in angiogenic branching or indirectly as a result of abnormal pulmonary epithelial development, particularly given that Nrp1 immunostaining was observed both in the developing microvasculature and the abluminal edge of the branching epithelium. Nevertheless, the in vitro migratory response of PMVECs toward Sema3c, as well as the importance of NRP1 in VEGF- and SEMA3-mediated endothelial migration, ${ }^{14}$ does suggest a defect in endothelial migration.

Although reduced Vegf and Vegfr2 expression was observed, this may have resulted from reduced capillary 

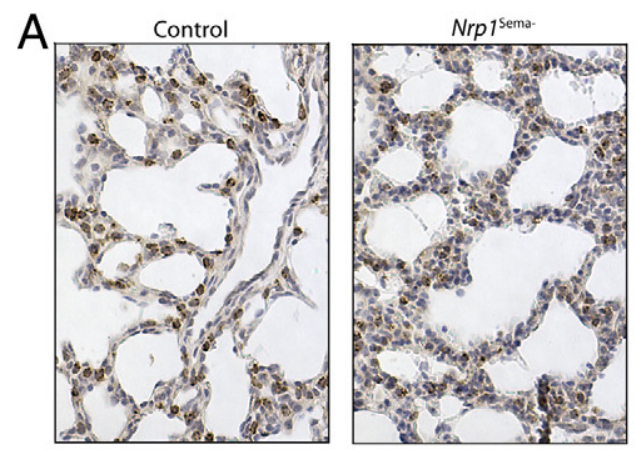

B
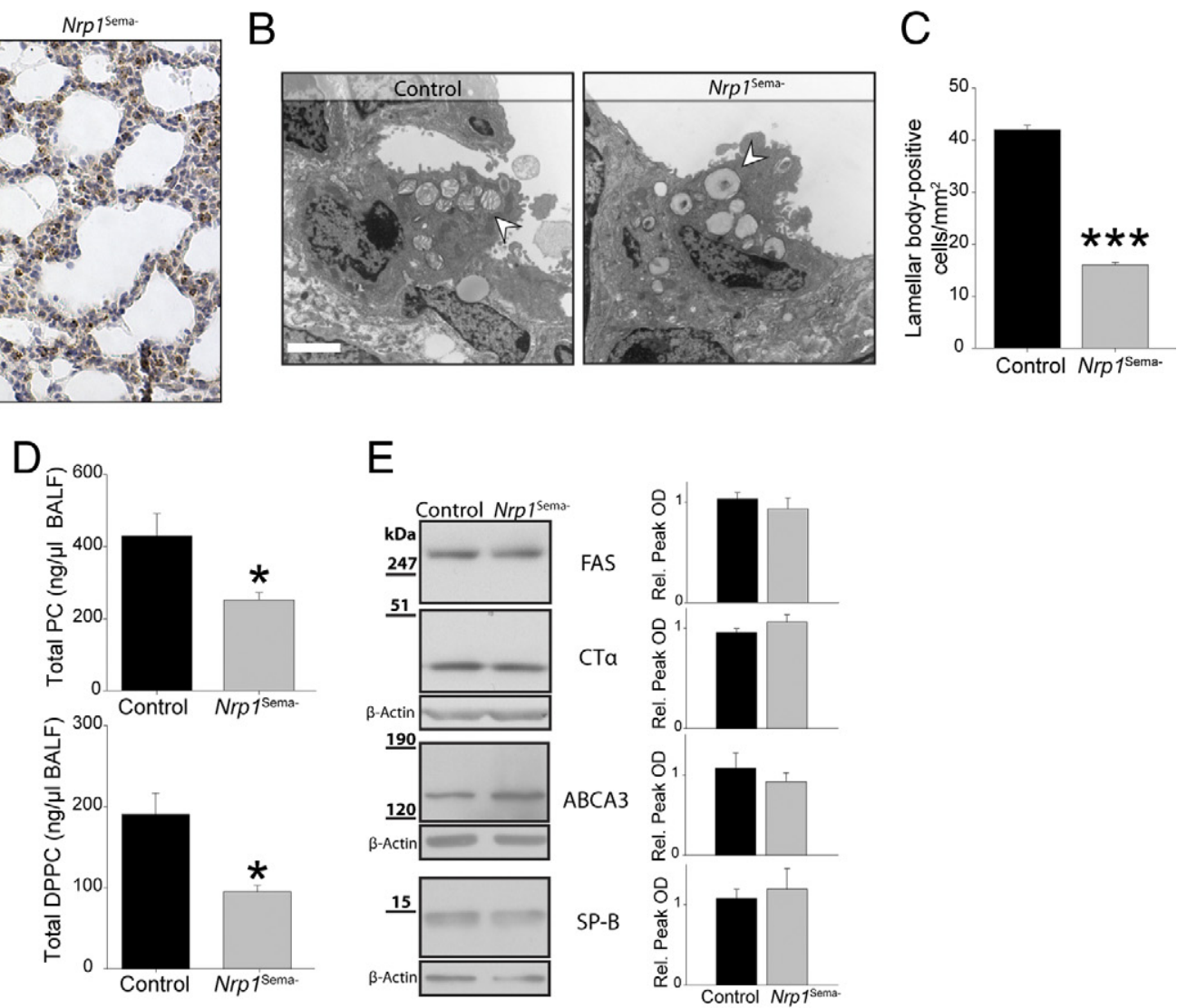

Figure 10. $N r p 1^{\text {Sema- }}$ mice present with decreased surfactant secretion. A: proSPC immunostaining showed positive reactivity in both $N r p 1^{\text {Sema- }}$ mutant and control mice. B: TEM at P1 showed that, although type II pneumocytes are morphologically observable in both controls and mutants (arrowheads), mutants often present with lamellar bodies deficient in phospholipid lamellae. C: Reduced lamellar body-containing type II pneumocytes were quantified in $N r p 1^{\text {Sema- }}$ mutants. D: Mass spectroscopy of bronchoalveolar lavage fluid showed reduced secretion of total PCs, particularly the essential surface-active species DPPC, in $N r p 1^{\text {Sema- }}$ mutants. E: Representative immunoblots show that reduced surfactant secretion was not attributable to genes involved in surfactant synthesis [fatty acid synthase (FAS); choline phosphate cytidylyltransferase (CT $\alpha)$ ] or lamellar body packaging [ATP-binding cassette subfamily A member 3 (ABCA3); surfactant protein B (SP-B)]. Densitometry data were quantified relative to $\beta$-actin $(n=8)$. ${ }^{*} P<0.05$; ${ }^{* * * *} P<0.001 . n=100$ fields from 2 animals per group $(\mathbf{C})$; $n \geq 6$ (D). Scale bar $=2 \mu \mathrm{m}(\mathbf{B})$. Original magnification, $\times 200(\mathbf{A})$.

density and/or disrupted microvascular signaling pathways. No significant change in expression was observed in CD31, a general marker of the endothelium, although this may be because normal expression of the intact large vasculature masked changes in the smaller distal microvasculature, whereas Vegf-Vegfr-2 signaling, being critical for normal microvascular development at this stage, may have been significantly disrupted. Indeed, only the Vegf $_{188}$ isoform, which is critical during perinatal microvascular development, ${ }^{46,48}$ was significantly reduced in Nrp1 ${ }^{\text {Sema- }}$ mutants. Likewise, the reduced expression of Foxf1, an essential transcription factor implicated in clinical ACD, suggests a disruption of microvascular programming, particularly in light of its numerous transcriptional targets. ${ }^{34,35}$ Whether SEMA3NRP1 signaling is more directly involved in altering the VEGF-VEGFR-2 pathway remains to be determined.

Airspace patency was observed in E18.5 Nrp1 ${ }^{\mathrm{Sema}-}$ mutants, because the lungs had not yet undergone the transition from fluid to air respiration, when surfactant secretion becomes essential to prevent airspace collapse. ${ }^{42}$ In contrast, $\mathrm{Nrp}^{\text {Sema- }}$ lungs at P1 presented with large atelectatic regions in the lung periphery, consistent with surfactant deficiency. This was confirmed by the reduced se- cretion of essential surfactant PCs, the observation of fewer lamellar body-containing cells, and by the frequent observation of lamellar bodies devoid of phospholipid lamellae. Decreased surfactant secretion was not attributable to a reduction of key enzymes involved in PC synthesis or genes essential for phospholipid incorporation and lamellar body packaging, ${ }^{42}$ suggesting instead a lack of substrate availability for PC synthesis arising from insufficient vascularization of the parenchyma.

Postnatally, Nrp1 ${ }^{\text {Sema- }}$ mice present with reduced saccular area and thickened septa, which further suggests a delay in lung maturation. Indeed, a lack of myofibroblast recruitment in mutants reflects septal immaturity, although it is unclear if this is a consequence of reduced parenchymal maturation or disrupted myofibroblast recruitment. Moreover, vSMC attachment to both arterioles and venules was significantly reduced, suggestive of either a failure of VSMC recruitment or further evidence of a general delay in vessel maturation; normal pericyte recruitment to the microvascular endothelium favors the latter interpretation. Smooth muscle proliferation was observed in arterioles associated with abnormal veins, likely reflective of hypertensive changes arising from dysmorphic pulmonary circulation. 
Although rarely diagnosed, ACD has come to be suspected in infants with idiopathic pulmonary hypertension refractory to vasodilator treatment. ${ }^{49,50}$ Persistent hypertension in ACD probably arises from the primary developmental deficit in pulmonary vascular branching, rather than the absence of a normal reduction in pulmonary vascular resistance or excessive prenatal distal vasculature muscularization. ${ }^{49}$ Importantly, several cases of lateonset presentation or less severe manifestations compatible with prolonged survival have been described, suggesting an incomplete assessment of the clinical spectrum and prevalence of ACD. ${ }^{49-51}$ Indeed, the degree of capillary density and apposition to the epithelium among several ACD lung biopsies appeared to have prognostic value in a retrospective examination. ${ }^{52}$ The somewhat varied histological presentation and the survival of some $\mathrm{Nrp}{ }^{\mathrm{Sema}-}$ mutants beyond the early neonatal period may thus be explained by attenuated but adequate microvascular development. A variety of extrapulmonary malformations have also been described in $A C D$, including patent ductus arteriosus, interrupted aortic arch, and gastrointestinal anomalies, ${ }^{34}$ all of which have been noted in mice deficient in Sema3a, Sema3c, or Nrp1. ${ }^{18,19,53}$

Because of inherent postnatal lung immaturity, infants who have undergone abnormal microvascular development or those born prematurely are susceptible to respiratory distress, often necessitating prolonged assisted ventilation. Nevertheless, many survivors do not achieve normal alveolar development, resulting in the chronic lung disease bronchopulmonary dysplasia (BPD), characterized histologically by an arrest in alveolar septation and dysmorphic vascular growth. ${ }^{54}$ Despite their disparate presentation, severity, and clinical course, ACD and BPD nonetheless share common features. Arrested development is a consistent histological finding (whether during the midembryonic stages of microvascular ingrowth or during postnatal alveolarization), along with microvascular paucity, thickened septa, and pulmonary hypertensive changes. Misexpression of angiogenic factors, both in the antenatal and postnatal periods, has frequently been demonstrated in BPD infants, ${ }^{54-56}$ as well as in experimental $A C D, 8,46$ implicating abnormal pulmonary vascular development as an essential mechanism of pathogenesis in certain lung diseases of infancy. Whether aberrant SEMA3-NRP1 signaling contributes toward the development of dysmorphic vasculature in the postnatal period, and thus the pathogenesis of $\mathrm{BPD}$, remains an open question.

To conclude, we have shown that SEMA3-NRP1 signaling is crucial for fetal pulmonary development, because loss of Sema3-Nrp1 signaling in our mouse model resulted in severe respiratory distress and abnormal pulmonary vascular development with features reminiscent of clinical ACD.

\section{Acknowledgment}

We thank Angie Griffin-Aizic for her excellent technical support in mouse colony maintenance.

\section{References}

1. Galambos C, deMello D: Molecular mechanisms of pulmonary vascular development. Pediatr Dev Pathol 2007:10:1-17

2. Le Cras TD, Markham NE, Tuder RM, Voelkel NF, Abman SH: Treatment of newborn rats with a VEGF receptor inhibitor causes pulmonary hypertension and abnormal lung structure. Am J Physiol Lung Cell Mol Physiol 2002, 283:L555-L562

3. McGrath-Morrow SA, Cho C, Zhen L, Hicklin DJ, Tuder RM: Vascular endothelial growth factor receptor 2 blockade disrupts postnatal lung development. Am J Respir Cell Mol Biol 2005, 32:420-427

4. Kunig AM, Balasubramaniam V, Markham NE, Morgan D, Montgomery G, Grover TR, Abman SH: Recombinant human VEGF treatment enhances alveolarization after hyperoxic lung injury in neonatal rats. Am J Physiol Lung Cell Mol Physiol 2005, 289:L529-L535

5. Lin YJ, Markham NE, Balasubramaniam V, Tang JR, Maxey A, Kinsella JP, Abman SH: Inhaled nitric oxide enhances distal lung growth after exposure to hyperoxia in neonatal rats. Pediatr Res 2005, 58: 22-29

6. Thébaud B, Ladha F, Michelakis ED, Sawicka M, Thurston G, Eaton F, Hashimoto K, Harry G, Haromy A, Korbutt G, Archer SL: Vascular endothelial growth factor gene therapy increases survival, promotes lung angiogenesis, and prevents alveolar damage in hyperoxia-induced lung injury: evidence that angiogenesis participates in alveolarization. Circulation 2005, 112:2477-2486

7. Bishop NB, Stankiewicz P, Steinhorn RH: Alveolar capillary dysplasia Am J Respir Crit Care Med 2011, 184:172-179

8. Han RN, Babaei S, Robb M, Lee T, Ridsdale R, Ackerley C, Post M Stewart DJ: Defective lung vascular development and fatal respiratory distress in endothelial NO synthase-deficient mice: a model of alveolar capillary dysplasia? Circ Res 2004, 94:1115-1123

9. Kagoshima M, Ito T: Diverse gene expression and function of semaphorins in developing lung: positive and negative regulatory roles of semaphorins in lung branching morphogenesis. Genes Cells 2001, 6:559-571

10. Chung L, Yang TL, Huang HR, Hsu SM, Cheng HJ, Huang PH: Semaphorin signaling facilitates cleft formation in the developing salivary gland. Development 2007, 134:2935-2945

11. Gu C, Yoshida Y, Livet J, Reimert DV, Mann F, Merte J, Henderson CE, Jessell TM, Kolodkin AL, Ginty DD: Semaphorin 3E and plexin-D1 control vascular pattern independently of neuropilins. Science 2005 , 307:265-268

12. Serini G, Valdembri D, Zanivan S, Morterra G, Burkhardt C, Caccavari F, Zammataro L, Primo L, Tamagnone L, Logan M, Tessier-Lavigne M, Taniguchi M, Püschel AW, Bussolino F: Class 3 semaphorins control vascular morphogenesis by inhibiting integrin function [Erratum appeared in Nature 2003, 424:974]. Nature 2003, 424:391-397

13. Pellet-Many C, Frankel $P$, Jia $H$, Zachary I: Neuropilins: structure, function and role in disease. Biochem J 2008, 411:211-226

14. Pan Q, Chanthery Y, Liang WC, Stawicki S, Mak J, Rathore N, Tong RK, Kowalski J, Yee SF, Pacheco G, Ross S, Cheng Z, Le Couter J, Plowman G, Peale F, Koch AW, Wu Y, Bagri A, Tessier-Lavigne M, Watts RJ: Blocking neuropilin-1 function has an additive effect with anti-VEGF to inhibit tumor growth. Cancer Cell 2007, 11:53-67

15. Soker S, Miao HQ, Nomi M, Takashima S, Klagsbrun M: VEGF165 mediates formation of complexes containing VEGFR-2 and neuropilin-1 that enhance VEGF165-receptor binding. J Cell Biochem 2002, 85:357-368

16. Salikhova A, Wang L, Lanahan AA, Liu M, Simons M, Leenders WP, Mukhopadhyay D, Horowitz A: Vascular endothelial growth factor and semaphorin induce neuropilin-1 endocytosis via separate pathways [Erratum appeared in Circ Res 2010, 107: e14]. Circ Res 2008, 103:e71-79

17. Behar O, Golden JA, Mashimo H, Schoen FJ, Fishman MC: Semaphorin III is needed for normal patterning and growth of nerves, bones and heart. Nature 1996, 383:525-528

18. Feiner L, Webber AL, Brown CB, Lu MM, Jia L, Feinstein P, Mombaerts P, Epstein JA, Raper JA: Targeted disruption of semaphorin 3C leads to persistent truncus arteriosus and aortic arch interruption. Development 2001, 128:3061-3070

19. Gu C, Rodriguez ER, Reimert DV, Shu T, Fritzsch B, Richards LJ, Kolodkin AL, Ginty DD: Neuropilin-1 conveys semaphorin and VEGF 
signaling during neural and cardiovascular development. Dev Cell 2003, 5:45-57

20. Reidy KJ, Villegas G, Teichman J, Veron D, Shen W, Jimenez J, Thomas D, Tufro A: Semaphorin3a regulates endothelial cell number and podocyte differentiation during glomerular development. Development 2009, 136:3979-3989

21. Bates D, Taylor GI, Minichiello J, Farlie P, Cichowitz A, Watson N, Klagsbrun M, Mamluk R, Newgreen DF: Neurovascular congruence results from a shared patterning mechanism that utilizes Semaphorin3A and Neuropilin-1. Dev Biol 2003, 255:77-98

22. Vieira JM, Schwarz Q, Ruhrberg C: Selective requirements for NRP1 ligands during neurovascular patterning. Development 2007, 134: 1833-1843

23. Caniggia I, Tseu I, Han RN, Smith BT, Tanswell K, Post M: Spatial and temporal differences in fibroblast behavior in fetal rat lung. Am $J$ Physiol 1991, 261:L424-L433

24. Livak KJ, Schmittgen TD: Analysis of relative gene expression data using real-time quantitative PCR and the 2(-Delta Delta $\mathrm{C}(\mathrm{T})$ ) method. Methods 2001, 25:402-408

25. Yang J, Wang J, Tseu I, Kuliszewski M, Lee W, Post M: Identification of an 11-residue portion of CTP-phosphocholine cytidylyltransferase that is required for enzyme-membrane interactions. Biochem J 1997, 325:29-38

26. Kolodkin AL, Levengood DV, Rowe EG, Tai YT, Giger RJ, Ginty DD: Neuropilin is a semaphorin III receptor. Cell 1997, 90:753-762

27. Groenman FA, Rutter M, Wang J, Caniggia I, Tibboel D, Post M: Effect of chemical stabilizers of hypoxia-inducible factors on early lung development. Am J Physiol Lung Cell Mol Physiol 2007, 293:L557L567

28. Ridsdale R, Tseu I, Roth-Kleiner M, Wang J, Post M: Increased phosphatidylcholine production but disrupted glycogen metabolism in fetal type II cells of mice that overexpress CTP: phosphocholine cytidylyltransferase. J Biol Chem 2004, 279:55946-55957

29. Dutly AE, Kugathasan L, Trogadis JE, Keshavjee SH, Stewart DJ, Courtman DW: Fluorescent microangiography (FMA): an improved tool to visualize the pulmonary microvasculature. Lab Invest 2006, 86:409-416

30. Dong XR, Maguire CT, Wu SP, Majesky MW: Chapter 9. Development of coronary vessels. Methods Enzymol 2008, 445:209-228

31. Kawasaki T, Kitsukawa T, Bekku Y, Matsuda Y, Sanbo M, Yagi T, Fujisawa $\mathrm{H}$ : A requirement for neuropilin-1 in embryonic vessel formation. Development 1999, 126:4895-4902

32. Esselens C, Malapeira J, Colomé N, Casal C, Rodríguez-Manzaneque JC, Canals F, Arribas J: The cleavage of semaphorin 3C induced by ADAMTS1 promotes cell migration. J Biol Chem 2010, 285:2463-2473

33. Banu N, Teichman J, Dunlap-Brown M, Villegas G, Tufro A: Semaphorin $3 \mathrm{C}$ regulates endothelial cell function by increasing integrin activity. FASEB J 2006, 20:2150-2152

34. Stankiewicz P, Sen P, Bhatt SS, Storer M, Xia Z, Bejjani BA, et al: Genomic and genic deletions of the FOX gene cluster on 16q24.1 and inactivating mutations of FOXF1 cause alveolar capillary dysplasia and other malformations. Am J Hum Genet 2009, 84:780-791

35. Kalinichenko VV, Lim L, Stolz DB, Shin B, Rausa FM, Clark J, Whitsett JA, Watkins SC, Costa RH: Defects in pulmonary vasculature and perinatal lung hemorrhage in mice heterozygous null for the Forkhead Box f1 transcription factor. Dev Biol 2001, 235:489-506

36. King J, Hamil T, Creighton J, Wu S, Bhat P, McDonald F, Stevens T: Structural and functional characteristics of lung macro- and microvascular endothelial cell phenotypes. Microvasc Res 2004, 67:139151

37. Rossignol M, Gagnon ML, Klagsbrun M: Genomic organization of human neuropilin-1 and neuropilin-2 genes: identification and distribution of splice variants and soluble isoforms. Genomics 2000, 70: 211-222
38. Gaengel K, Genové G, Armulik A, Betsholtz C: Endothelial-mural cell signaling in vascular development and angiogenesis. Arterioscler Thromb Vasc Biol 2009, 29:630-638

39. HellströM M, Kalén M, Lindahl P, Abramsson A, Betsholtz C: Role of PDGF-B and PDGFR-beta in recruitment of vascular smooth muscle cells and pericytes during embryonic blood vessel formation in the mouse. Development 1999, 126:3047-3055

40. Weibel ER: On pericytes, particularly their existence on lung capillaries. Microvasc Res 1974, 8:218-235

41. Lindahl P, Karlsson L, HellströM M, Gebre-Medhin S, Willetts K, Heath JK, Betsholtz C: Alveogenesis failure in PDGF-A-deficient mice is coupled to lack of distal spreading of alveolar smooth muscle cell progenitors during lung development. Development 1997, 124:39433953

42. Wert SE, Whitsett JA, Nogee LM: Genetic disorders of surfactant dysfunction. Pediatr Dev Pathol 2009:12:253-274

43. Goerke J: Pulmonary surfactant: functions and molecular composition. Biochim Biophys Acta 1998, 1408:79-89

44. Schwarz MA, Caldwell L, Cafasso D, Zheng H: Emerging pulmonary vasculature lacks fate specification. Am J Physiol Lung Cell Mol Physiol 2009, 296:L71-L81

45. Gebb SA, Shannon JM: Tissue interactions mediate early events in pulmonary vasculogenesis. Dev Dyn 2000, 217:159-169

46. Galambos C, Ng YS, Ali A, Noguchi A, Lovejoy S, D'Amore PA, deMello DE: Defective pulmonary development in the absence of heparin-binding vascular endothelial growth factor isoforms. Am J Respir Cell Mol Biol 2002, 27:194-203

47. Vacca A, Scavelli C, Serini G, Di Pietro G, Cirulli T, Merchionne F, Ribatti D, Bussolino F, Guidolin D, Piaggio G, Bacigalupo A, Dammacco F: Loss of inhibitory semaphorin 3A (SEMA3A) autocrine loops in bone marrow endothelial cells of patients with multiple myeloma. Blood 2006, 108:1661-1667

48. Ng YS, Rohan R, Sunday ME, Demello DE, D'Amore PA: Differential expression of VEGF isoforms in mouse during development and in the adult. Dev Dyn 2001, 220:112-121

49. Ahmed S, Ackerman V, Faught P, Langston C: Profound hypoxemia and pulmonary hypertension in a 7-month-old infant: late presentation of alveolar capillary dysplasia. Pediatr Crit Care Med 2008, 9:e43e46

50. Shankar V, Haque A, Johnson J, Pietsch J: Late presentation of alveolar capillary dysplasia in an infant. Pediatr Crit Care Med 2006, 7:177-179

51. Abdallah HI, Karmazin N, Marks LA: Late presentation of misalignment of lung vessels with alveolar capillary dysplasia. Crit Care Med 1993, 21:628-630

52. Melly L, Sebire NJ, Malone M, Nicholson AG: Capillary apposition and density in the diagnosis of alveolar capillary dysplasia. Histopathology 2008, 53:450-457

53. Anderson RB, Bergner AJ, Taniguchi M, Fujisawa H, Forrai A, Robb L, Young HM: Effects of different regions of the developing gut on the migration of enteric neural crest-derived cells: a role for Sema3A, but not Sema3F. Dev Biol 2007, 305:287-299

54. Bhatt AJ, Pryhuber GS, Huyck H, Watkins RH, Metlay LA, Maniscalco WM: Disrupted pulmonary vasculature and decreased vascular endothelial growth factor. Flt-1, and TIE-2 in human infants dying with bronchopulmonary dysplasia Am J Respir Crit Care Med 2001, 164: 1971-1980

55. De Paepe ME, Patel C, Tsai A, Gundavarapu S, Mao Q: Endoglin (CD105) up-regulation in pulmonary microvasculature of ventilated preterm infants. Am J Respir Crit Care Med 2008, 178:180-187

56. Tang JR, Karumanchi SA, Seedorf G, Markham N, Abman SH: Excess soluble vascular endothelial growth factor receptor-1 in amniotic fluid impairs lung growth in rats: linking preeclampsia with bronchopulmonary dysplasia. Am J Physiol Lung Cell Mol Physiol 2012, 302:L36L46 